Discussion

Papers

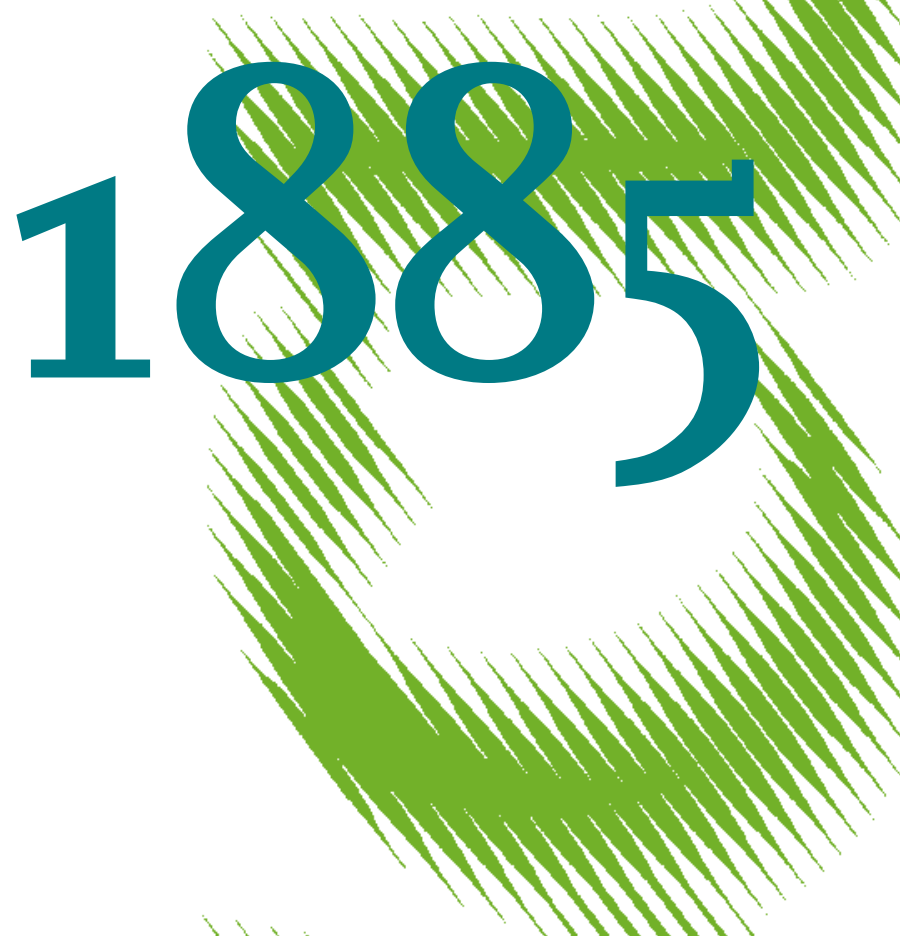

Substituting Clean for Dirty Energy: A Bottom-Up Analysis 
Opinions expressed in this paper are those of the author(s) and do not necessarily reflect views of the institute.

IMPRESSUM

(C) DIW Berlin, 2020

DIW Berlin

German Institute for Economic Research

Mohrenstr. 58

10117 Berlin

Tel. +49 (30) $89789-0$

Fax +49 (30) $89789-200$

http://www.diw.de

ISSN electronic edition 1619-4535

Papers can be downloaded free of charge from the DIW Berlin website:

http://www.diw.de/discussionpapers

Discussion Papers of DIW Berlin are indexed in RePEc and SSRN:

http://ideas.repec.org/s/diw/diwwpp.html

http://www.ssrn.com/link/DIW-Berlin-German-Inst-Econ-Res.html 


\title{
Substituting Clean for Dirty Energy: A Bottom-Up Analysis*
}

\author{
Fabian Stöckl ${ }^{\dagger} \ddagger$ (D), Alexander Zerrahn ${ }^{\ddagger}$
}

August 6, 2020

\begin{abstract}
We fit CES and VES production functions to data from a numerical bottom-up optimization model of electricity supply with clean and dirty inputs. This approach allows for studying high shares of clean energy not observable today and for isolating mechanisms that impact the elasticity of substitution between clean and dirty energy. Central results show that (i) dirty inputs are not essential for production. As long as some energy storage is available, the elasticity of substitution between clean and dirty inputs is above unity; (ii) no single clean technology is indispensable, but a balanced mix facilitates substitution; (iii) substitution is harder for higher shares of clean energy. Finally, we demonstrate how changing availability of generation and storage technologies can be implemented in macroeconomic models.
\end{abstract}

JEL codes: O44, Q42, Q43, Q55

Keywords: Elasticity of substitution, clean and dirty energy, electricity production, decarbonization, green growth

\footnotetext{
*We thank Martin Kittel, Michael Knoblach, Melanie Koch, Julia Rechlitz, Alexander Roth, and Marica Valente for many valuable comments that helped to significantly improve this paper. We gratefully acknowledge financial support within the project The Economics of Climate Change - The Future of Fossil Fuels in the Wake of Greenhouse Gas Neutrality (FFF), funded by the Federal Ministry of Education and Research (FKZ 01LA1810B).

${ }^{\dagger}$ Technische Universität Berlin, Germany.

${ }^{\ddagger}$ German Institute for Economic Research (DIW Berlin), Germany.
} 


\section{Introduction}

As of 2020, anthropogenic $\mathrm{CO}_{2}$ emissions have caused global warming of around one degree Celsius, adversely affecting many dimensions of (human) life. To mitigate a further rise in temperatures, the use of fossil fuels must be substantially reduced (IPCC, 2014). Since thermodynamic laws limit energy efficiency gains in production (Meran, 2019), substituting clean, renewable inputs for dirty, $\mathrm{CO}_{2}$ emitting inputs is key (Bretschger, 2005).

In many macroeconomic models, especially growth models, the elasticity of substitution captures how difficult it is to replace dirty with clean inputs in production. It also determines whether, in the long-run, a complete shift from dirty to clean inputs is feasible or not. In general, an elasticity of substitution above unity is necessary to avoid a climate disaster (Acemoglu et al., 2012; Hémous, 2016; Greaker et al., 2018). Yet a profound bottom-up view on the top-down elasticity of substitution is missing (Mattauch et al., 2015). This especially concerns its technological determinants and its development for high shares of clean inputs not observable today, but central for a future clean economy. We fill this gap.

We generate production isoquants with a numerical bottom-up optimization model of electricity supply that takes both economic and technological aspects into account. Based on these data, we fit aggregate production functions and the corresponding elasticity of substitution between clean and dirty inputs. As we control the data generating process, we can both derive insights on the cleandirty substitutability, also for high shares of clean inputs that are not yet observable, and isolate channels that affect the elasticity of substitution. In our analysis, we focus on electricity generation, a major source of anthropogenic $\mathrm{CO}_{2}$ emissions (IPCC, 2014; IEA, 2019a). With the ongoing electrification of transportation, heating, and industrial processes, the electricity sector will gain further importance in the future. Thus, the sector's elasticity of substitution also gains relevance as an approximation for the elasticity of substitution for aggregate production as used in macroeconomic models.

We make four contributions. First, using simulated data allows for examining substitution patterns not observable to their full extent yet. This especially applies to high future shares of clean energy sources that are a central part of climate policies in many countries and entail a transformative change of the energy supply structure. By contrast, empirical analyses today must rely on data for only moderate shares. These contain only limited information on high penetration rates of clean energy (Koetse et al., 2008; Ueckerdt et al., 2015). We 
give support to this conjecture by showing that substitution rates for low shares of clean energy cannot necessarily be transferred to future settings with high shares.

Second, using a numerical bottom-up model allows for isolating the mechanisms that shape the elasticity of substitution between clean and dirty inputs. Our model accounts for the most relevant clean energy technologies, incorporating their technological and economic characteristics. This comprises different types of energy storage as well as weather-dependent wind and solar electricity, whose supply does not necessarily match demand in time. In the model, we switch on or off single technologies to inspect how their availability impacts substitution possibilities. Our results show that dirty inputs are not essential for production and that a balanced mix of clean generation and storage technologies most easily substitutes dirty inputs. No single clean technology is indispensable. Yet without any storage, substitution becomes particularly hard for high shares of clean energy.

Third, we apply both a production function with a constant elasticity of substitution (CES), as often used in empirical and theoretical research, and a more flexible variant with a variable elasticity of substitution (VES). The latter allows for the possibility that substitution may become over-proportionately difficult with a rising share of clean energy. Both specifications show a good fit to the simulated data. When extrapolating substitution patterns from low to high shares of clean inputs, the CES function tends to underestimate required clean inputs, while the VES function tends to overestimate it. Given necessary abstractions in the numerical model, the CES specification likely fits real-world data better.

Fourth, we show that installed generation capacities, a common input measure (see Papageorgiou et al., 2017), can give rise to non-convex production isoquants. That is, capacities do not necessarily reflect an increasing difficulty in the substitution of clean for dirty energy sources, but rather the contrary. We suggest the sum of investment and variable costs as an alternative input measure that captures the idea of increasingly difficult substitution, is easy to interpret, and can readily be used in macroeconomic models.

Our paper is most closely related to Papageorgiou et al. (2017). Employing a binary distinction between clean and dirty inputs, they estimate the elasticity of substitution for a panel of industry-level data from 26 OECD countries for the years 1995-2009. Imposing a CES structure on production, Papageorgiou et al. (2017) find a cross-country elasticity of about 1.8 in the electricity-generating 
sectors, which implies that dirty inputs are not essential for electricity production. In an extension, Malikov et al. (2018) abandon the CES structure and apply non-parametric estimation methods. They find an elasticity of substitution above unity only for about two-thirds of the observations. Moreover, their results suggest that the assumption of a constant elasticity of substitution needs to be rejected in favor of a more flexible structure.

In contrast, Wiskich (2019), using a theoretical model of electricity generation based on generic aggregate clean and dirty inputs, demonstrates that the degree of substitutability may decrease for future high shares of clean inputs. Similar to Malikov et al. (2018), he shows that more flexible structures can approximate the decreasing elasticity of substitution predicted by his electricity generation model better than the CES approach. Like Wiskich (2019), we use an ex ante model. Yet we explicitly implement several pivotal aspects of electricity production, like an explicit time resolution that captures the temporal variability of renewable supply and the central role of storage. This allows for deriving more and richer conclusions, also relating to the theoretical literature and existing empirical evidence.

The remainder of this paper is structured as follows. Sections 2 and 3 introduce the numerical model, data, and scenario assumptions. Section 4 discusses two different input measures and the resulting production isoquants. The fitting of production functions is explained in Section 5. Section 6 presents the results, and Section 7 discusses limitations as well as implications for theoretical and empirical research. Section 8 concludes.

\section{Numerical Model}

We analyze production in the electricity sector with a numerical bottom-up optimization model. It takes into account the central economic and technological trade-offs between clean and dirty technologies. The model minimizes the total costs of electricity supply over one year in hourly resolution. Thus, it determines the first-best benchmark from the perspective of a benevolent social planner with perfect foresight and complete information. With all capacities endogenous, the solution mimics an equilibrium on a frictionless electricity market with perfect competition. The model is a linear program that is numerically solved to global 
optimality. For transparency and reproducibility (Pfenninger, 2017), model code and all input data are available open-source under a permissive license. ${ }^{1}$

Exogenous model inputs comprise costs and availability limits for each technology as well as hourly time series of electricity demand and availability of renewable energy sources. Endogenous model variables are investments and consecutive hourly use for all electricity generation and storage technologies. The model result is the cost-minimizing capacity mix of clean and dirty technologies as well as the corresponding investment and operational costs for an exogenously set share of clean generation. The model focuses on one country and abstracts from an explicit spatial resolution.

The objective function (1a) sums the annualized investment and annual fixed costs $\kappa^{i}$ for storage $(s t)$ as well as clean $(c l)$ and dirty $(d i)$ generation capacities $N .^{2}$ Operational costs $\kappa^{v}$ accrue for hourly electricity supply $G_{h}$ from dirty technologies as well as storage loading $\vec{S}_{h}$ and storage energy withdrawal $\overleftarrow{S}_{h}$.

$$
\begin{aligned}
Z= & \sum_{d i} \kappa_{d i}^{i} N_{d i}+\sum_{c l} \kappa_{c l}^{i} N_{c l}+\sum_{s t}\left(\vec{\kappa}_{s t}^{i} \vec{N}_{s t}+\overleftarrow{\kappa}_{s t}^{i} \overleftarrow{N}_{s t}+\kappa_{s t}^{i} N_{s t}\right) \\
& +\sum_{h}\left[\sum_{d i} \kappa_{d i}^{v} G_{h, d i}+\sum_{s t}\left(\overleftarrow{\kappa}^{v} \overleftarrow{S}_{h, s t}+\vec{\kappa}^{v} \vec{S}_{h, s t}\right)\right]
\end{aligned}
$$

As dirty technologies, we denote conventional plants that emit $\mathrm{CO}_{2}$ through burning fossil fuels, such as natural gas power stations. As clean technologies, we denote renewable plants that do not emit $\mathrm{CO}_{2}$ when operating, such as wind and solar power. Beyond emissions, clean and dirty technologies differ in two important respects.

First, clean technologies do not incur variable costs because they do not require any fuel to operate. Dirty technologies require fossil fuels that come at a cost. This difference is reflected in the objective function (1a). Second, the supply of dirty technologies is dispatchable. Their full capacity is available in each hour, and plants can generate electricity whenever required or optimal in terms of the model's objective. The supply of clean technologies is variable. This variability, also referred to as intermittency, means that plants cannot be switched on at discretion, but generate electricity according to natural conditions, i.e., in hours when the wind blows or the sun shines. These hours do not necessarily coincide

\footnotetext{
${ }^{1}$ This numerical model is a variant of the power sector model DIETER; in previous research, it is used to analyze questions on renewable energy and electrical storage (Zerrahn and Schill, 2017; Zerrahn et al., 2018). Code and data are available under Stöckl and Zerrahn (2020).

${ }^{2}$ Throughout the exposition, capital Roman letters denote variables, small Roman letters sets, and Greek letters parameters.
} 
with hours of high demand. Therefore, electrical storage assumes a mediating role to align supply and demand in time.

For the different storage technologies st, investments into storage power input $\vec{N}_{s t}$, power output $\overleftarrow{N}_{s t}$, and storage energy $N_{s t}$ capacities are mutually independent. The storage power capacities specify how much electricity can enter or leave the storage in an hour; the energy capacity specifies how much energy can be kept inside the storage.

A market-clearing condition (1b) equates electricity demand $\delta_{h}$ and supply in hourly resolution, as is standard in many electricity markets. The left-hand side is augmented by electricity demand that flows into storage; the right-hand side contains electricity supply from storage. As is standard in numerical bottomup models, we assume that short-run electricity demand is inelastic. Electricity can hardly be substituted by other energy carriers in the short run, and most customers do not see real-time prices. Therefore, we assume that the demand side does not adjust its intended electricity consumption on a short time scale.

$$
\delta_{h}+\sum_{s t} \vec{S}_{h, s t}=\sum_{d i} G_{h, d i}+\sum_{c l} G_{h, c l}+\sum_{s t} \overleftarrow{S}_{h, s t} \quad \forall h
$$

Capacity bounds $\nu$ for each technology may constrain investment according to spatial or political limitations (1c), and generation of dirty plants may be no larger than installed capacities (1d). For the variable clean technologies, time series of exogenous capacity factors $\phi_{h, c l} \in[0,1]$ render their hourly availability. Excess renewable electricity supply can be curtailed at no cost, indicated by the inequality in Equation (1e), and does not have to be integrated into the marketclearing condition through storage. In that way, the model trades off storage investments with investments in renewable energy sources whose excess supply is not used at times (Zerrahn et al., 2018).

$$
\begin{array}{ccc}
N_{d i} \leq \nu_{d i}, \quad N_{c l} \leq \nu_{c l}, \quad \overleftarrow{N}_{s t} \leq \overleftarrow{\nu}_{s t}, \quad \vec{N}_{s t} \leq \vec{\nu}_{s t}, & N_{s t} \leq \nu_{s t} & \forall c l, d i, s t \\
G_{h, d i} \leq N_{d i} & \forall h, d i \\
G_{h, c l} \leq \phi_{h, c l} N_{c l} & \forall h, c l
\end{array}
$$

The filling level of a storage $S_{h, s t}$ equals the filling level in the previous hour plus the energy that enters the storage and minus the energy that leaves the storage (1f). Storage filling and withdrawal are subject to losses, represented by the respective efficiency $\eta_{s t}$. An additional constraint equates the filling levels in the first and last periods. Storage input, output, and filling levels may not exceed 
installed capacities $(1 \mathrm{~g})$. Likewise, storage input may not exceed the currently available volume of the storage, and storage output may not exceed the current filling level (1h). To impose a realistic relation between power and energy investments, electricity from a full storage can be supplied for at most $\tau_{s t}$ hours (1i). For simplicity, we may impose equal investments into installed capacities for storing in and out.

$$
\begin{gathered}
S_{h, s t}=S_{h-1, s t}+\vec{\eta}_{s t} \vec{S}_{h, s t}-\frac{1}{\eta_{s t}} \overleftarrow{S}_{h, s t} \quad \forall h, s t \\
\vec{S}_{h, s t} \leq \vec{N}_{s t}, \quad \overleftarrow{S}_{h, s t} \leq \overleftarrow{N}_{s t}, \quad S_{h, s t} \leq N_{s t} \quad \forall, h, s t \\
\vec{\eta}_{s t} \vec{S}_{h, s t} \leq N_{s t}-S_{h-1, s t}, \quad \frac{1}{\bar{\eta}_{s t}} \overleftarrow{S}_{h, s t} \leq S_{h-1, s t} \quad \forall h, s t \\
N_{s t} \leq \tau_{s t} \overleftarrow{N}_{s t} \quad \forall s t, \quad \overleftarrow{N}_{s t}=\vec{N}_{s t}
\end{gathered}
$$

Eventually, Equation (1j) implements that generation by clean technologies must match a pre-specified share $\iota \in[0,1]$ in overall annual electricity generation. If only one dirty technology is available, this approach is equivalent to implementing a varying level of emissions. We later vary this share to analyze substitution between clean and dirty inputs.

$$
\sum_{h, c l} G_{h, c l}=\iota \sum_{h}\left(\sum_{c l} G_{h, c l}+\sum_{d i} G_{h, d i}\right)
$$

\section{Input Data and Scenarios}

To concisely focus on the peculiarities of clean and storage technologies, we consider natural gas as the only available dirty technology. From the perspective of the numerical model, other dirty technologies such as coal do not qualitatively impact the substitution between clean and dirty. As they are dispatchable and have positive variable costs, they share the central characteristics of natural gas. Sensitivity calculations show that results are preserved when coal is an option. Additionally, from a policy perspective, more emission-intensive coal plants are a worse fit for a low-carbon energy supply.

Clean technologies comprise wind power - both onshore and offshore - as well as solar photovoltaics. As mature renewable technologies, they are central in long-term energy outlooks in the decarbonization strategies of many countries (IEA, 2019b). Moreover, their potential is less limited than for hydro energy, for which many good sites are already exploited. For one scenario, we also 
consider electricity generation from biomass and hydro energy as clean technologies. $^{3}$

We consider the three most mature types of electrical storage: lithium-ion batteries, pumped-hydro storage, and power-to-gas storage. These three technologies show a trade-off concerning the specific investment costs for power and energy capacities. Batteries have low investment costs for storage power and high costs for energy. This means that large investments into energy capacities are rather uneconomical, rendering them a suitable short-term storage for a few hours. In contrast, power-to-gas storage has high specific investment costs for power capacities - electrolyzers and fuel cells that convert electricity to hydrogen and back - but low costs for energy capacities. Thus, it is a suitable long-term storage for several weeks. The ratio of investment costs for pumped-hydro storage is in between, rendering it a medium-term storage. For convenience, investments into capacities for storing in and out are equal for batteries and pumped-hydro storage. This does not apply to power-to-gas storage because electrolyzers, for storing in, and fuel cells, for storing out, are, in any case, separate objects.

Numerical assumptions on costs and availability of all technologies are based on established medium-term projections for Germany. Appendix A.2 gives a full description of the input data. Variable costs of dirty plants are derived from fuel costs and technological efficiency. As we implement the level of clean generation through a mandatory quota $(1 \mathrm{j})$, we do not consider costs for emission certificates. Annualized specific investment costs are derived from overnight investment costs and the technical lifetime of plants.

To study technological possibilities for substitution, we vary the share $\iota$ of clean generation in total annual electricity generation (1j) between 0 and $95 \%$ in one-percentage-point increments. The result is the hull of the cost-minimizing combinations of clean and dirty electricity generation and storage capacities, i.e., the production isoquants. In a later step, these capacity data, and derived cost data, are used to fit the CES and VES production functions as a continuous representation of electricity generation from clean and dirty inputs.

In general, the model can accommodate shares up to $100 \%$, yet we argue that the analysis of such high shares is not reasonable in this framework. Given long-term climate policies, it is not conceivable to see $100 \%$ clean electricity generation in isolation without taking into account the decarbonization of other

\footnotetext{
${ }^{3}$ Hydro energy supply is also variable and has no variable costs. Biomass combustion incurs variable costs and is dispatchable, i.e., does not depend on exogenous weather conditions. To account for biomass resource availability, an additional model constraint limits annual generation to 7000 hours per year at maximum capacity, leaning on values for Germany.
} 
energy end uses, like mobility or heat. These would add new demand patterns and temporal flexibility, in turn, impacting the substitutability between clean and dirty energy. Section 6.4 presents a stylized model extension; yet a detailed treatment is beyond the scope of this paper. The bar of $95 \%$ is high enough to observe very high shares of clean inputs, but low enough not to give rise to implausible results. For convenience, we start with $0.01 \%$ clean energy; a share of zero percent can imply a division by zero when fitting the production functions. This minor technical point does not alter the findings.

A number of scenarios (Table 1) systematically explore how different technologies affect the scope for substitution. Scenario Germany leans on Papageorgiou et al. (2017). It features the clean, non-emitting energy sources onshore wind, offshore wind, and solar photovoltaics (PV), as well as run-of-river hydro power and biomass. Dirty technologies comprise natural gas plants. As scheduled by German policy, coal power is not part of the energy mix. All three storage technologies are available. Except for natural gas plants, batteries, and power-to-gas storage, capacities require sizable dedicated space. For instance, wind and solar power cannot be deployed in arbitrary amounts within a country. Therefore, in scenario Germany, we assume upper bounds for investments according to established projections given German spatial resources. As such projections vary, we pursue a conservative approach and pick pessimistic values for the potential expansion of clean technologies in Germany (Table A.2). In line with German legislation, nuclear power is no option for electricity generation.

To derive more general insights on the determinants of substitutability, seven stylized scenarios depart from the German setting and allow for generally unlimited investments in clean technologies (Table 1). Scenario All features natural gas, wind, and solar power as well as all three storage types. Four scenarios vary the availability of storage (No sto, No bat, No phs, No p2g), and two scenarios vary the availability of clean generation technologies (Wind only, PV only). Focusing on readily scalable clean technologies, we do not consider run-of-river hydro and biomass power, whose capacities are either largely exploited or highly limited. Thus, it is little insightful to assume future expansions. 
Table 1: Scenarios

\begin{tabular}{|c|c|c|c|c|c|c|c|c|c|}
\hline & \multirow{2}{*}{$\begin{array}{c}\text { Dirty } \\
\begin{array}{c}\text { Natural } \\
\text { gas }\end{array}\end{array}$} & \multicolumn{8}{|c|}{ Clean } \\
\hline & & $\begin{array}{c}\text { Wind } \\
\text { onshore }\end{array}$ & $\begin{array}{l}\text { Wind } \\
\text { offshore }\end{array}$ & PV & $\begin{array}{c}\text { Bio } \\
\text { energy }\end{array}$ & $\begin{array}{l}\text { Run- } \\
\text { of-river } \\
\text { hydro }\end{array}$ & $\begin{array}{l}\text { Battery } \\
\text { storage }\end{array}$ & $\begin{array}{l}\text { Pumped- } \\
\text { hydro } \\
\text { storage }\end{array}$ & $\begin{array}{l}\text { Power- } \\
\text { to-gas } \\
\text { storge }\end{array}$ \\
\hline Germany & $\times$ & $\times$ & $\times$ & $\times$ & $\times$ & $\times$ & $x$ & $x$ & $x$ \\
\hline All & $x$ & $\times$ & $\times$ & $\times$ & & & $x$ & $x$ & $x$ \\
\hline No sto & $\times$ & $x$ & $x$ & $x$ & & & & & \\
\hline No bat & $x$ & $x$ & $x$ & $x$ & & & & $x$ & $x$ \\
\hline No phs & $\times$ & $\times$ & $\times$ & $\times$ & & & $x$ & & $x$ \\
\hline No p2g & $x$ & $x$ & $x$ & $\times$ & & & $x$ & $x$ & \\
\hline Wind only & $\times$ & $\times$ & $\times$ & & & & $\times$ & $x$ & $\times$ \\
\hline$P V$ only & & & & $x$ & & & $x$ & $x$ & $x$ \\
\hline
\end{tabular}

\section{Measuring Clean and Dirty Inputs}

In the following, we take the results of the numerical model for each share of clean energy as data and analyze the resulting production isoquants. These give a first understanding of the substitution between clean and dirty inputs.

\subsection{Non-Convex Production Isoquants}

To start with, we employ clean and dirty production capacities (in gigawatts, GW) as input measure, as commonly used in the literature (see, e.g., Papageorgiou et al., 2017). Figure 1 shows the resulting production isoquant based on our simulated data for scenario Germany. For storage, we take the output capacity because it adds to generation. Any storage that is already installed for zero percent clean energy is added proportionately to dirty and clean capacities according to the share of clean and dirty energy. ${ }^{4}$ All storage beyond this baseline dirty-only value is added to clean capacities because it is built to complement rising clean energy shares.

\footnotetext{
${ }^{4}$ Specifically, for zero percent clean energy, all storage capacities are added to dirty inputs; for one percent clean energy, one percent of the storage capacities installed for zero percent clean energy are added to clean capacities and 99 percent to dirty capacities, and so forth. This assignment only applies to the minor part of storage that is already installed for zero percent clean energy.
} 


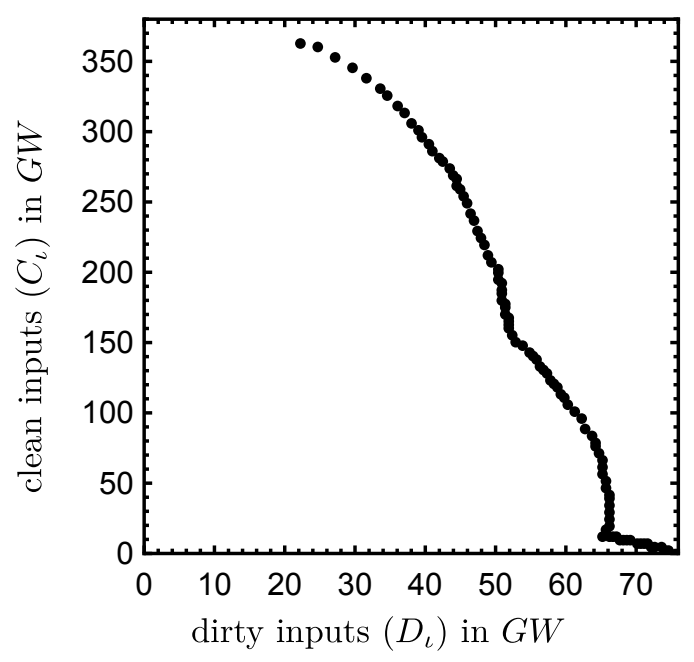

Figure 1: Production Isoquant Using Clean and Dirty Capacities - Scenario Germany

Given the temporal variability of clean renewable generation - the supply of wind and solar power varies with daytime, season, and weather conditions and does not have to coincide with demand - one should expect that substituting clean for dirty inputs becomes more difficult as the share of clean inputs rises, yielding a convex production isoquant. This is also what some empirical papers conclude (e.g., Papageorgiou et al., 2017). Yet the isoquant for our simulated data is non-convex, showing concave segments separated by kinks. Analogous findings also prevail for all other scenarios, where kinks separate concave, occasional linear, and convex parts. Concavity implies an increasing marginal product of input factors, rather than a decreasing or constant one. Puzzling at first glance, we argue that capacities are not a meaningful proxy for inputs because they do not reflect the underlying substitution in electricity generation. In general, capacities are not equal to generation, which is the quantity of interest. ${ }^{5}$

Using capacities as input measure, isoquants are shaped by typical characteristics of clean electricity generation. Specifically, the concave segments are due to storage. It helps to make better use of clean but variable wind and solar power. Without storage, the proportion of clean energy from wind or solar power that exceeds demand in an hour must be curtailed. The optimization model trades off cost-minimal investments into storage and clean generation. Instead of overproportionately greater clean generation capacities, smaller but cost-intensive

\footnotetext{
${ }^{5}$ Appendix A.1 discusses how to reconcile a capacity-based, convex production isoquant as estimated by Papageorgiou et al. (2017) with our simulated data.
} 
investments into storage are optimal and better exploit clean capacity additions. In particular, this applies to high shares of clean energy, where situations in which clean supply exceeds demand occur more frequently. The kinks in the isoquants are due to limited potentials to invest in certain technologies that arise from country idiosyncrasies such as spatial limitations. If a potential limit is reached, investment must resort to the next expensive technology to raise the share of clean generation.

\subsection{A New Measure}

Instead of installed capacities (in GW), we suggest using clean and dirty electricity system costs (ESC, in Euros) of capacities. They comprise investment, fixed, and variable costs of generation and storage, as also captured by the objective function of the numerical model. ${ }^{6}$ As above, for the minor part of storage already built for a case without clean generation, costs are attributed to the dirty and clean ESC proportionately to the share of dirty and clean energy. Costs of any further storage that complements clean energy expansion are attributed to the clean ESC. ${ }^{7}$ All costs refer to a specified time interval, in our case a year, with investment costs annualized and variable costs summed up. Figure 2 shows the corresponding isoquant for scenario Germany.

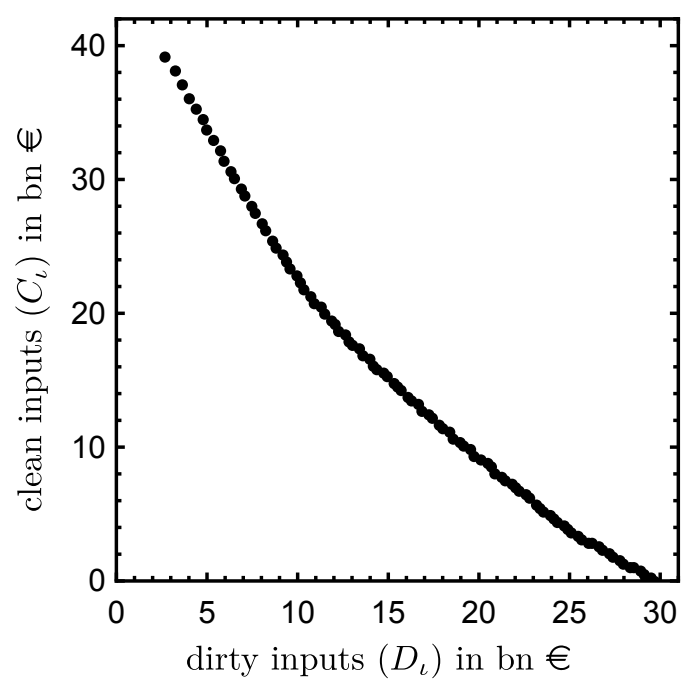

Figure 2: Production Isoquants Using Clean and Dirty Electricity System Costs - Scenario Germany

\footnotetext{
${ }^{6}$ Appendix A.3 gives a formal definition using the nomenclature of the numerical optimization model.

${ }^{7}$ In a sensitivity analysis, Papageorgiou et al. (2017) also use a metric based on investment costs of generation capacities but neglect variable costs. Applied to our simulated data, isoquants are again non-convex.
} 
Using ESC has several advantages over generation capacities. First, they carry the notion that substitution of clean for dirty generation becomes increasingly difficult for high shares of renewables. While it does not necessarily become harder capacity-wise, costs rise over-proportionately due to the variability of clean generation. A diversified clean capacity mix between wind and solar helps to supply electricity more evenly. This diversified mix must resort to technologies that are more expensive, yet available at times when cheaper renewable generation is not. Additionally, for medium to high shares of clean energy, more costly storage investment complements variable clean generation.

Second, ESC fully capture the trade-off between investment, fixed, and variable costs characterizing clean and dirty generation technologies. In general, variable clean technologies have rather high specific investment costs, but zero variable costs. In contrast, dirty technologies, such as natural gas plants, have relatively low specific investment costs and high variable costs.

Third, ESC directly provide information on substitution costs. These would be difficult to retrieve from aggregate clean and dirty capacities as they comprise various technologies at a broad range of costs. Moreover, as a cost metric, ESC readily apply to more aggregate macroeconomic models - either as annual flows in terms of final good production/money or, alternatively, as short-lived (one year) capital stock assigned to clean and dirty electricity generation, respectively. In the latter case, one can interpret variable inputs, such as natural gas, as being provided by a part of the dirty capital stock assigned to drilling capacities. ${ }^{8}$

Finally, the elasticity of substitution obtains an intuitive interpretation when using ESC: the higher the elasticity of substitution, the lower the increase in the exchange rate between clean and dirty inputs - i.e., the marginal rate of technical substitution - as the share of clean inputs increases. That is, ceteris paribus, for an increasing share of clean inputs, the clean ESC increase less if the elasticity of substitution is higher. ${ }^{9}$

\section{$5 \quad$ Fitting Procedure}

Using our simulated data, we fit two widely used types of production functions. First, we fit the standard two-input CES production function introduced by Ar-

\footnotetext{
${ }^{8}$ In macroeconomic models, inertia of the power sector can be introduced by extending capital stock lifetime and the depreciation period, with input costs increasing proportionately.

${ }^{9}$ Formally, the elasticity of substitution is defined as $\sigma \equiv \frac{d \ln (D / C)}{d \ln \left(M R T S_{C, D}\right)}$, where $C$ and $D$ denote the clean and dirty ESC, respectively.
} 
row et al. (1961) and also used by Papageorgiou et al. (2017). We apply a factor-neutral, time-invariant efficiency parameter, but abstract from directed technological change over time because technology-specific efficiencies are constant in our numerical bottom-up model. The resulting CES production function reads:

$$
E_{\iota}=A\left(\alpha C_{\iota}^{\frac{\sigma-1}{\sigma}}+(1-\alpha) D_{\iota}^{\frac{\sigma-1}{\sigma}}\right)^{\frac{\sigma}{\sigma-1}}+\varepsilon_{\iota},
$$

where $\iota$ denotes the share of clean generation for the simulated data points. The output is total electricity generation $E_{\iota}$ in megawatt hours, $C_{\iota}, D_{\iota} \geq 0$ are clean and dirty inputs in terms of ESC, $A>0$ is overall efficiency, the parameter $\alpha \in$ $(0,1)$ captures the relative importance of inputs, the elasticity of substitution is captured by $\sigma \in(0, \infty)$, and $\varepsilon_{\iota}$ is the error term. ${ }^{10}$

Second, for the alternative VES production function, the elasticity of substitution depends on the ratio of clean to dirty inputs, $c_{\iota}=C_{\iota} / D_{\iota}$. This represents the idea that, ceteris paribus, substitutability can change with rising shares of clean inputs. We use the following parsimonious specification introduced by Re$\operatorname{vankar}(1971):^{11}$

$$
E_{\iota}=A D_{\iota}^{a}\left[C_{\iota}+b a D_{\iota}\right]^{(1-a)}+\varepsilon_{\iota}
$$

with the parameter constraints $a \in(0,1], b>-1$ and $c_{\iota} \geq-b$. These parameter constraints guarantee that the standard properties of a neoclassical production function are fulfilled (Karagiannis et al., 2005). The input ratio-dependent elasticity of substitution is given by:

$$
\sigma\left(c_{\iota}\right)=1+\frac{b}{c_{\iota}}>0
$$

for which $\sigma \gtreqless 1$ if $b \gtreqless 0$. That is, depending on $b$, the elasticity of substitution is either always above or below unity and decreases or increases in $c_{\iota}$, respectively. ${ }^{12}$

Following the existing literature (e.g., Papageorgiou et al., 2017; Kemfert, 1998; Bodkin and Klein, 1967), we determine the production function parameters with the best fit using a nonlinear optimization that minimizes the mean squared error with respect to output (MSE). ${ }^{13}$ Also the comparison of the CES and VES specifications as well as their prediction performance is based on the MSE. We do

\footnotetext{
${ }^{10}$ For convenience, we do not consider the special cases of a Leontief, Cobb-Douglas, and von Neumann production functions, i.e., $\sigma=0, \sigma=1$, and $\sigma=\infty$.

${ }^{11}$ See Karagiannis et al. (2005) for a detailed discussion of the properties of this specification of a VES production function.

${ }^{12}$ Growiec and Mućk (2019) develop more flexible VES specifications where the elasticity can cross the threshold value of unity. Yet, in general, these variants lack a closed-form representation.

${ }^{13}$ Mathematica code is available under Stöckl and Zerrahn (2020)
} 
not use the $R^{2}$ because it is not valid for nonlinear models (Spiess and Neumeyer, 2010).

\section{Results}

\subsection{General Results}

Table 2 shows the fitted elasticities of substitution for the CES and VES production functions taking the clean and dirty ESC as inputs. ${ }^{14}$ We use three different samples of the simulated data: the full $\left(c_{0}-c_{95}\right)$ sample, a lower $\left(c_{0}-c_{50}\right)$ sample, and a higher $\left(c_{51}-c_{95}\right)$ sample. The lower sample represents shares of clean energy as mostly observed today. The higher sample represents a future setting.

Table 2: Fitted Elasticity of Substitution $(\sigma)$

\begin{tabular}{|c|c|c|c|c|c|c|}
\hline & \multicolumn{3}{|c|}{ CES } & \multicolumn{3}{|c|}{ VES } \\
\hline & full & lower & higher & full & lower & higher \\
\hline & $\sigma$ & $\sigma$ & $\sigma$ & $\sigma_{c_{0}} \rightarrow \sigma_{c_{95}}$ & $\sigma_{c_{0}} \rightarrow \sigma_{c_{50}}$ & $\sigma_{c_{51}} \rightarrow \sigma_{c_{95}}$ \\
\hline Germany & 3.94 & 6.13 & 3.25 & $>1000 \rightarrow 1.22$ & $>1000 \rightarrow 2.29$ & $9.79 \rightarrow 1.58$ \\
\hline$A l l$ & 6.46 & 13.32 & 5.66 & $>1000 \rightarrow 1.51$ & $>1000 \rightarrow 4.14$ & $17.61 \rightarrow 2.21$ \\
\hline No sto & 1.84 & 9.09 & 0.94 & $>1000 \rightarrow 1.04$ & $>1000 \rightarrow 2.97$ & $0.88 \rightarrow 0.99$ \\
\hline No bat & 6.46 & 13.32 & 5.66 & $>1000 \rightarrow 1.51$ & $>1000 \rightarrow 4.14$ & $17.62 \rightarrow 2.21$ \\
\hline No phs & 5.57 & 10.68 & 6.67 & $>1000 \rightarrow 1.40$ & $>1000 \rightarrow 3.38$ & $23.60 \rightarrow 2.42$ \\
\hline No p $2 g$ & 3.88 & 12.38 & 1.60 & $>1000 \rightarrow 1.22$ & $>1000 \rightarrow 3.88$ & $2.99 \rightarrow 1.15$ \\
\hline Wind only & 5.44 & 9.47 & 7.51 & $>1000 \rightarrow 1.35$ & $>1000 \rightarrow 3.01$ & $29.39 \rightarrow 2.51$ \\
\hline PV only & 3.28 & 5.29 & 1.81 & $>1000 \rightarrow 1.21$ & $>1000 \rightarrow 1.95$ & $3.54 \rightarrow 1.23$ \\
\hline
\end{tabular}

As our first central result, the elasticity of substitution is always above unity as long as some storage is available. This holds for both the CES and VES specifications. That is, given there is some flexibility to integrate variable renewable electricity, the elasticity of substitution of the fitted production functions indicates that dirty inputs are not essential for electricity production and that a complete shift to clean inputs is feasible. This finding also preserves the results

\footnotetext{
${ }^{14}$ Table A.5 presents a complete list of all fitted parameters.
} 
of the numerical bottom-up model, in which electricity supply can be completely satisfied with clean inputs. ${ }^{15}$

Second, for the CES specification, the elasticity of substitution in the higher sample is always smaller than in the lower sample. That is, substitution is more difficult for higher shares of clean inputs. Adding greater amounts of clean energy requires increasingly costly investments in respective capacities. Also in the VES specification, the elasticity in the higher sample decreases to smaller values than in the lower sample. Moreover, in the VES specification, the elasticity of substitution falls in the share of clean generation, except for the scenario without storage. $^{16}$

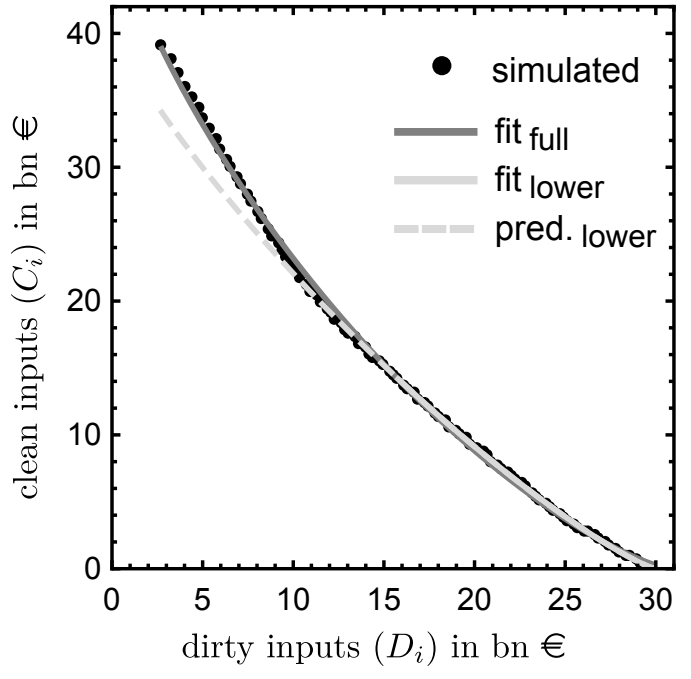

(a) CES

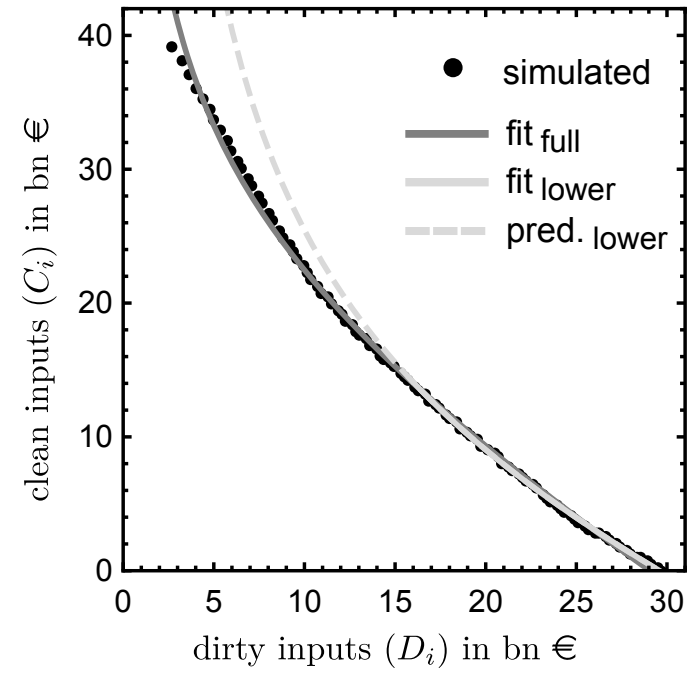

(b) VES

Figure 3: Fitted Production Functions for the Full Sample and Predicted Production Functions Based on the Lower Sample - Scenario Germany

Third, in all scenarios, both production functions have a good fit for the simulated data. While the MSE (given in squared megawatt hours, $\mathrm{MWh}^{2}$ ), as our optimality criterion (Table 3), does not have an intuitive interpretation, the good

\footnotetext{
${ }^{15}$ In the numerical model, $100 \%$ clean inputs are feasible even without storage (scenario $\mathrm{No}$ sto), yet the fitted CES and VES production functions pick up a massive cost increase for high shares of clean energy. By extrapolating this cost increase to the highest shares, which are not included in this analysis, the fitted functions wrongly imply essentiality of dirty inputs for the higher sample, i.e., $\sigma<1$.

${ }^{16}$ Yet, even for an increasing elasticity of substitution, as in the higher sample of scenario No sto, the difficulty of substituting clean for dirty inputs measured in absolute terms, i.e., the marginal rate of technical substitution (MRTS), always increases.
} 
fit of the CES and VES production function becomes clear from Figure 3, which depicts the best-fit production isoquants for the full sample in scenario Germany. It illustrates the gap between predicted (solid dark gray line) and required clean inputs (black dots) for given production and dirty inputs, represented by the vertical distance between the fitted production isoquant and the simulated data points. Averaged over all clean generation shares, the gap (in absolute terms) amounts to around 0.30 and 0.35 billion euros for the fitted CES and VES production functions, respectively, compared to 31.45 billion euros of average total ESC. This low gap highlights the good fit for scenario Germany. In the other scenarios, the fitted production functions also show a good fit (Tables A.3 and A.4 and Figures A.1-A.7).

In most scenarios, the CES function provides a slightly better fit than the VES in terms of the MSE. This is due to the rather restrictive (linear) evolution of the elasticity implied by the VES production function and the predetermined convergence to, or divergence from, unity (Equation 4). Only in three scenarios where central technologies are unavailable (No sto, No p2g, PV only), does the VES specification fit the simulated data better. Here, costs to accommodate very high shares of clean generation rise sharply, which seems to be better represented by the VES.

Table 3: Mean Squared Error (MSE) w.r.t. output $(E)$ - in $\mathrm{MWh}^{2}$

\begin{tabular}{ccccc}
\hline & full & lower & higher & higher $\left.\right|_{\text {lower }}$ \\
\hline CES & $2.455 \cdot 10^{13}$ & $1.332 \cdot 10^{12}$ & $8.378 \cdot 10^{12}$ & $7.269 \cdot 10^{14}$ \\
VES & $3.463 \cdot 10^{13}$ & $3.496 \cdot 10^{12}$ & $1.775 \cdot 10^{13}$ & $2.808 \cdot 10^{15}$ \\
\hline
\end{tabular}

Calculation: $\left(\left|\hat{Y}_{\iota}-Y_{\iota}\right|_{D_{\iota}, C_{\iota}}\right)^{2} / n$, where $\hat{Y}_{\iota}$ is predicted output of the fitted production function given $D_{\iota}$ and $C_{\iota}$. n denotes the number of data points.

Note: higher| $\left.\right|_{\text {lower }}$ is the MSE of the higher sample based on the fitted parameters of the lower sample.

Fourth, while both CES and VES show a good fit within the sample, they differ with respect to out-of-sample predictions. This is especially relevant if one is interested in substitution patterns for high shares of clean energy when only data for low shares is available. If we fit the CES function for the lower sample (solid light gray line) and extrapolate it to the higher sample (dashed light gray line), this underestimates the necessary clean inputs as Figure 3a illustrates for scenario Germany. This reflects that the elasticity of substitution for the lower 
sample has a greater numerical value than for the higher sample. Consequently, the MSE in that branch of the production function is higher (Table 3). By contrast, the VES function, when based on the lower sample, overestimates the necessary investment in clean inputs for the higher sample (Figure 3b). The VES approach picks up a rate of decrease for the elasticity of substitution from the lower sample that is too large for the higher sample. For scenario Germany, the average gap (in absolute terms) between predicted and required clean inputs in the higher sample is 1.46 billion euros for the CES and 6.16 for the VES, compared to average ESC of 34.00 billion euros. Qualitatively, the same results hold for the other scenarios (Tables A.3 and A.4 and Figures A.1-A.7). Only if no storage is available (scenario No sto), also the VES function underestimates costs for higher shares if based on the lower sample.

\subsection{Availability of Clean Technologies}

In the following, we derive results on how specific clean technologies impact the substitutability between clean and dirty inputs. For convenience, we only consider the fitted CES function because it is more tractable, common, and generally performs no worse than the VES approach.

\section{Storage}

If no storage is available (scenario No sto), demand must be covered by dirty generation from natural gas whenever the supply of clean renewable energy is low. This makes achieving high shares of clean energy difficult, reflected by a particularly low elasticity for the higher sample (Table 2). For low shares of clean energy, the absence of storage is less relevant, indicated by an elasticity of substitution well above unity for the lower sample. Thus, when only considering the lower sample, the central relevance of storage for high shares of renewable clean energy is not sufficiently reflected by the elasticity of substitution.

If storage investments are possible, the elasticity of substitution is substantially higher. By shifting energy from hours with high clean supply to hours of low clean supply but high demand, storage helps to even out the variability of wind and solar power. With more options available, also the costs of electricity production are necessarily lower (or equal) with storage compared to the case without storage for every share of clean generation.

Among the storage technologies, long-term power-to-gas storage sticks out. If only short-term batteries and medium-term pumped storage provide flexibility 
(scenario $N o p 2 g$ ), the substitutability of clean for dirty inputs is comparably low ( $\sigma=3.88$ for the full sample compared to $\sigma=6.46$ in scenario All). This effect is aggravated in the higher sample $(\sigma=1.60$ compared to $\sigma=5.66$ in scenario $A l l)$, but less pronounced in the lower sample $(\sigma=12.38$ compared to $\sigma=13.32$ in scenario $A l l)$. Thus, especially high shares of clean energy require long-term flexibility to serve demand at times with low renewable supply. For instance, in scenario $\mathrm{All}$, the power-to-gas storage bridges up to more than a month. In contrast, short-term batteries do not play a pivotal role (scenario $N_{o}$ $b a t)$.

\section{Clean Generation}

In general, no specific clean technology is indispensable. A geographical or institutional feature that may impede the deployment of a specific clean technology does not impede a full transition to clean production. Still, a diversified mix of clean capacities yields the highest elasticity of substitution. The full set of technologies can best exploit their complementary characteristics. If only wind is available (scenario Wind only), the elasticity of substitution is fitted with $\sigma=5.44$; if only solar photovoltaics is available (scenario $P V$ only), the elasticity of substitution is fitted with $\sigma=3.28$. Having both available (scenario All) raises the elasticity to $\sigma=6.46$.

This gives rise to two insights. First, as relatively cheap workhorse technology with a decent energy yield, wind power is a good foundation for the transition to clean energy. Second, costs, annual energy yield, and the timing of the energy yield of clean generation technologies complement each other. Photovoltaics is cheaper than onshore wind - investment costs per megawatt hour of potential energy output are around 35 euros compared to around 46 euros $^{17}$ - but the timing when solar energy is produced is less well aligned with demand. Its output is zero during nights and generally low during winter. Making the energy available when needed would require greater investments in storage. Therefore, a clean input combining temporally more even wind, low-cost solar, and different types of storage shows the lowest rate of cost increases if the share of clean energy rises. This is illustrated in Figure 4, showing the production isoquants with a cost break-down by clean technologies for scenarios All and PV only.

\footnotetext{
${ }^{17}$ Per unit of capacity, photovoltaics has both lower investment costs (by about half) and a lower annual energy yield (by about one-third) than onshore wind. Taken together, costs per potential energy output are lower. We denote the output as potential because excess generation may be curtailed.
} 


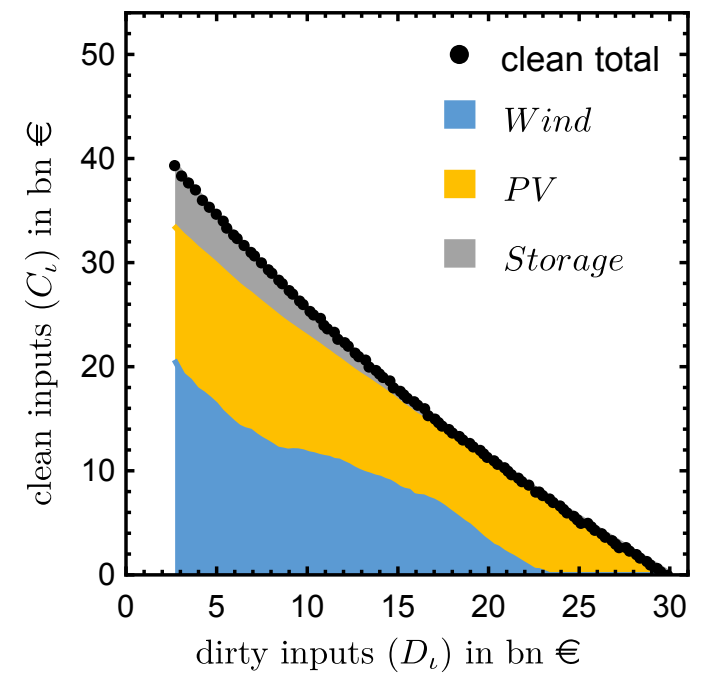

(a) Scenario All

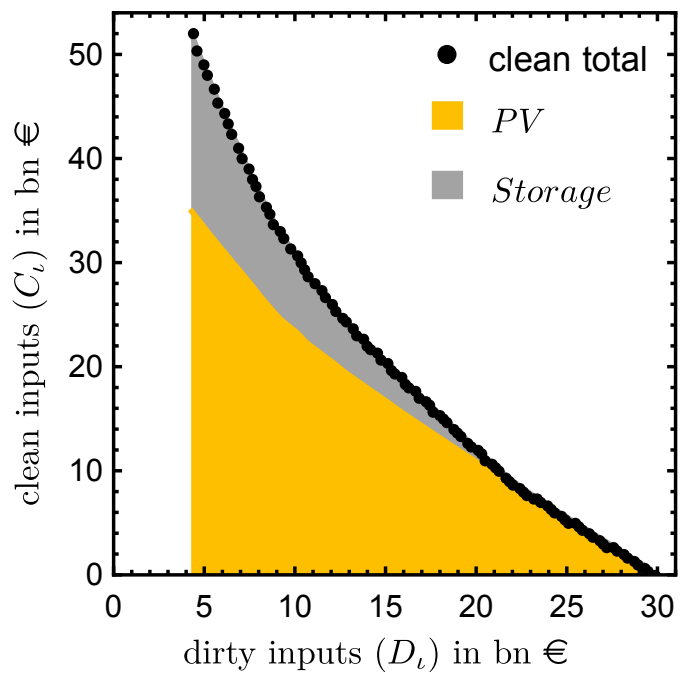

(b) Scenario $P V$ only

Figure 4: Production Isoquants and Cost Breakdown for Clean Technologies Scenario All

Finally, if generation capacities are limited, for instance, due to scarce sites for wind and solar power, the elasticity is lower (scenario Germany, $\sigma=3.94$ ), compared to the unrestricted optimum (scenario All, $\sigma=6.46$ ).

\section{Macroeconomic Representation of Technology Availability}

As a guidance for macroeconomic analysis, we find that changing the elasticity of substitution is well suited to reflect changing technology availability in a CES framework. We illustrate this point for scenarios Wind Only and No phs compared to scenario All.

Specifically, we first re-normalize the CES for a reference scenario $(A l l)$ in $c_{0}$ and then re-fit $\sigma$ to best fit the simulated data of the scenario of interest ( $N o$ phs, Wind only). ${ }^{18}$ Figure 5 illustrates the good fit for scenario All employing the elasticity of substitution $\tilde{\sigma}$ that is re-fitted to best fit scenarios Wind only and No phs, respectively. ${ }^{19}$

\footnotetext{
${ }^{18}$ Unlike for changing $\alpha$ and $A$, the elasticity of substitution has no effect on production in the normalization point. Given that the costs of electricity production converge to the same value for all scenarios with production entirely based on fossil fuels, $c_{0}$ appears as the 'natural' normalization point. See Klump et al. (2012) for an introduction to normalization.

${ }^{19}$ Re-fitting parameters $\alpha$ or $A$ instead yields two drawbacks. First, the reference scenario All and the re-fitted isoquant have no common starting point in $c_{0}$, where costs are equal. Second, the results have a worse fit compared to re-fitting $\sigma$.
} 


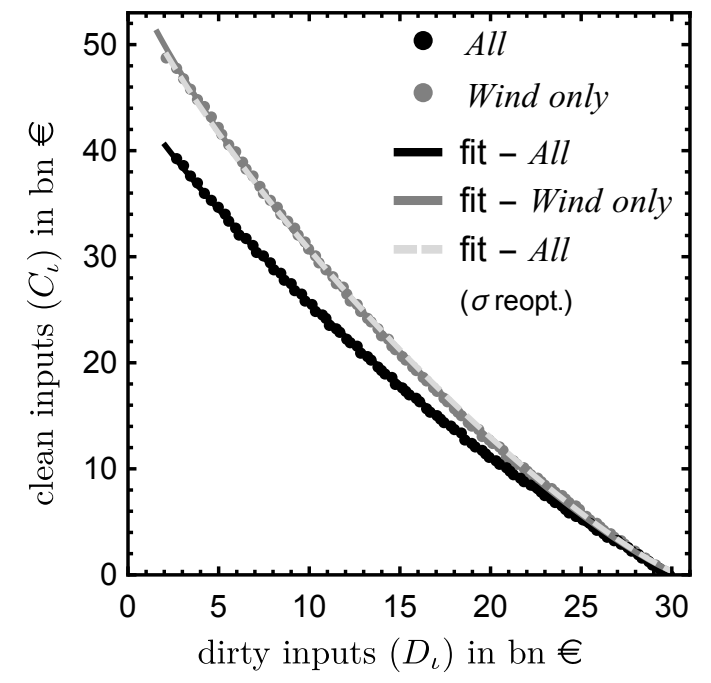

(a) Scenario Wind only

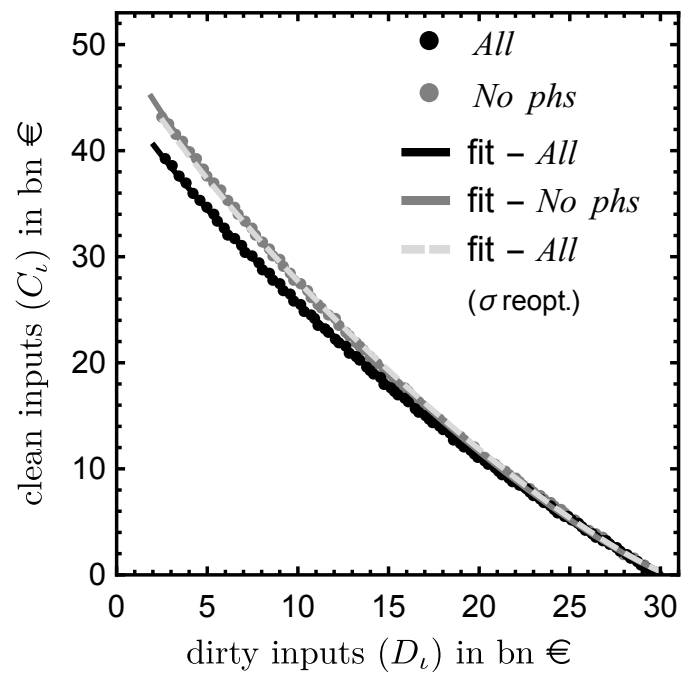

(b) Scenario No phs

Figure 5: Re-Fitted Elasticity of Substitution $\tilde{\sigma}$ for Scenarios Wind only and No phs, based on Scenario All

Consider the fully fitted scenarios first. Without pumped storage or with only wind (solid light gray lines), the clean ESC for non-zero shares of clean energy are higher and increase more strongly than in scenario All (solid black lines). This is also reflected by the lower elasticity of substitution. The isoquants based on the re-fitted elasticity of substitution $\tilde{\sigma}$ closely track this pivoting (dashed light gray lines). The re-fitted elasticities also closely resemble the elasticities in the fully fitted original scenario, yet are somewhat lower (Table 4). Likewise, at 0.242 and 0.238 billion euros, the average gaps between predicted and required clean inputs remain low compared to average overall ESC of 36.43 and 34.44 billion euros for scenarios Wind only and No phs, respectively. Still, they are slightly higher than in the fully fitted original scenarios.

Table 4: Re-Fitted Elasticity of Substitution $\tilde{\sigma}$

\begin{tabular}{lcccccc}
\hline & $\sigma$ & MSE & $\begin{array}{c}\text { Av. gap } \\
(\text { in bn } €)\end{array}$ & $\tilde{\sigma}$ & MSE & $\begin{array}{c}\text { Av. gap } \\
\text { (in bn } €) ~\end{array}$ \\
\hline All & 6.46 & $4.798 \cdot 10^{12}$ & 0.122 & & & \\
Wind only & 5.44 & $6.224 \cdot 10^{12}$ & 0.171 & 5.80 & $9.661 \cdot 10^{12}$ & 0.242 \\
No phs & 5.57 & $5.393 \cdot 10^{12}$ & 0.137 & 6.16 & $1.150 \cdot 10^{13}$ & 0.238 \\
\hline
\end{tabular}

Calculation: Production functions are renormalized in $c_{0}$ (see Klump et al., 2012). The elasticity $\tilde{\sigma}$ is obtained by re-optimizing $\sigma_{A l l}$ to best fit the simulated data of Wind only and No phs while holding $A_{A l l}$ and $\alpha_{A l l}$ constant. 


\subsection{Lower Costs of Clean Technologies}

A central question, especially when deriving policy recommendations from macroeconomic models, is whether lower costs of clean inputs change the elasticity of substitution. To this end, we fit CES functions in the most reduced and comprehensive scenarios (No sto, All) for sensitivities with costs for all clean and storage investments lower by $25 \%$ and $50 \%$.

Table 5: Elasticity of Substitution for Lower Costs of Clean Inputs

\begin{tabular}{lccc}
\hline & $\sigma$ & $\sigma_{-25 \%}$ & $\sigma_{-50 \%}$ \\
\hline No sto & 1.84 & 1.84 & 1.84 \\
All & 6.46 & 6.40 & 6.44 \\
\hline
\end{tabular}

Table 5 shows the resulting elasticities. Without storage, a uniform cost reduction that leaves the relative costs of inputs within the clean aggregate unchanged also leaves the elasticity of substitution unchanged. Moving along the production isoquant, the rate at which the ratio of clean and dirty costs evolves is identical. Yet the absolute cost increase is always lower (Figure 6a).

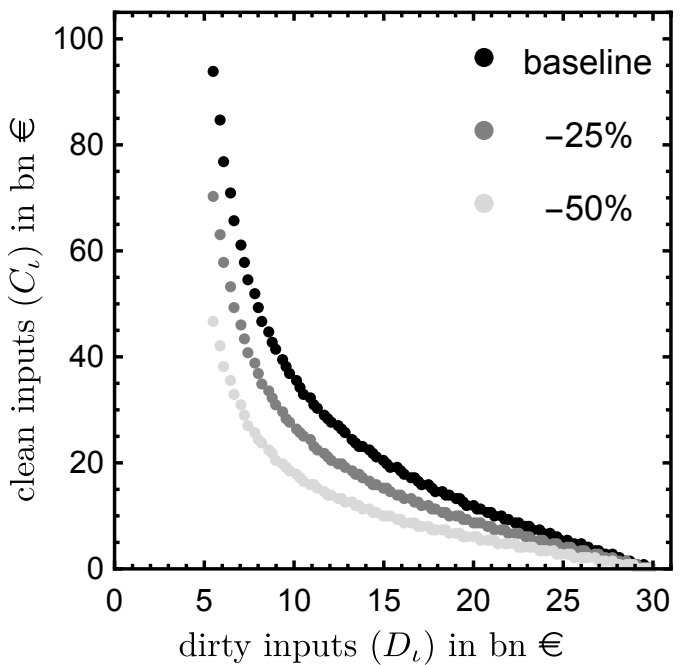

(a) Scenario No sto

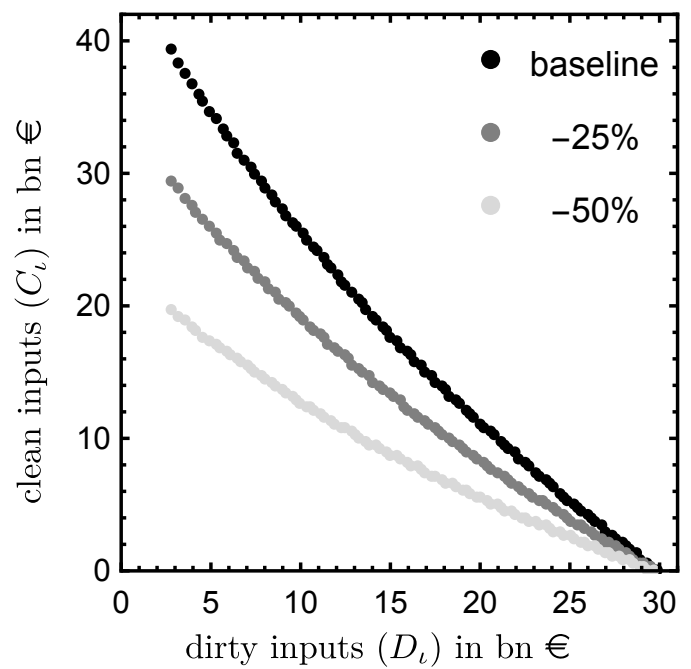

(b) Scenario All

Figure 6: Production Isoquants for Cost Sensitivities 
Qualitatively, the same result arises for the rich scenario All (Table 5), albeit the lower costs of all clean generation and storage technologies slightly alter the elasticity of substitution. The reason is that cheaper storage triggers higher optimal storage investments that benefit both clean and dirty generation. Also for dirty capacities, storage allows for shifting output to hours of high demand, increasing the utilization rate, and lowering optimal capacities. Thus, the costoptimal combination of clean and dirty inputs, and the elasticity of substitution, change to some extent as well. Also here, the absolute cost increase is lower, the more costs are reduced (Figure 6b).

As a central insight, a uniform cost reduction of clean inputs leaves the elasticity of substitution largely unaffected. This reflects that the elasticity captures the technological difficulty of replacing clean for dirty inputs. As a relative measure, it informs about cost changes, but is mute about absolute costs. Thus, for the same elasticity, absolute costs for a given share of clean inputs may differ substantially (Figure 6).

\subsection{Extension: Electrification of Other Sectors and Flex- ible Demand}

If climate goals are pursued stringently, energy demand beyond current electricity demand will be decarbonized through electrification based on clean electricity. This new demand from heating, mobility, or industry will likely be flexible, for instance, drawing on heat or chemical storages (IPCC, 2014). In a stylized model extension, we examine whether the additional temporal flexibility facilitates substitution, by allowing for making better use of excess renewable energy supply, or whether the additional demand makes substitution more difficult. To this end, we add a variable $D_{h}^{x}$ representing hourly electricity demand from an unspecified sector to the demand side of the market-clearing condition of the numerical model (1b).

$$
\delta_{h}+\sum_{s t} \vec{S}_{h, s t}+D_{h}^{x}=\sum_{d i} G_{h, d i}+\sum_{c} G_{h, c l}+\sum_{s t} \overleftarrow{S}_{h, s t} \quad \forall h
$$

We further assume that this additional demand in an hour must not exceed a threshold $\nu^{x}$, reflecting given capacities of some conversion facility, and must add up to a total of $\delta^{x}$ over the year, reflecting full flexibility when it is satisfied.

$$
D_{h}^{x} \leq \nu^{x} \quad \forall h, \quad \sum_{h} D_{h}^{x}=\delta^{x}
$$


We assume that $\delta^{x}$ is either $10 \%$ or $25 \%$ of annual current electricity demand, with $\nu^{x}$ equal to 20 or 50 gigawatts, respectively. Otherwise, the additional scenarios, denoted by $A l l_{X_{10 \%}}$ and $A l l_{X_{25 \%}}$, are identical to scenario $A l l$ and feature natural gas, wind and solar power as well as three storage types.

The results show that additional, but flexible, demand from electrification facilitates substitution of clean for dirty inputs. For the CES production function, the elasticity for the full sample is $\sigma=7.58$ and $\sigma=9.71$ for scenarios $A l l_{X_{10 \%}}$ and $A l l_{X_{25 \%}}$, respectively, compared to $\sigma=6.46$ in scenario All. Also for the VES production function, the elasticity decreases to higher values with flexible electrification of other sectors in place. ${ }^{20}$ Thus, if additional future electricity demand is sufficiently flexible, it helps to make better use of variable clean generation when it is available, enabling an easier substitution.

\section{Discussion}

\subsection{Limitations of the Numerical Bottom-Up Model}

The numerical model allows for inspecting mechanisms of electricity production not (yet) observable in empirical data. To this end, it requires assumptions on its boundaries and numerical inputs. Below, we discuss how these impact the results and the fitted elasticity of substitution.

Concerning model boundaries, we generally abstract from sources of flexibility beyond electrical storage. First, we analyze one generic country, based on data for Germany, in isolation and do not consider cross-border exchange of electricity. For larger geographical areas, supply of different clean technologies better complements each other, leading to a smoother temporal supply pattern (Brown et al., 2018; Schlachtberger et al., 2017). If wind is low in one place, it may be high in another. Second, current electricity demand, modeled as inelastic, will likely become more flexible. With the spread of digital energy management, private households and industrial processes can re-schedule planned consumption to times of high clean energy supply, although the literature suggests a rather modest positive effect on flexibility (Kwon and Østergaard, 2014; Schill and Zerrahn, 2018). In general, any further source of flexibility would enhance the substitutability of clean for dirty inputs as our extension for a generic electrification of other sectors shows (Section 6.4). As this is of special relevance for high shares

\footnotetext{
${ }^{20}$ Complete results are compiled in Table A.5.
} 
of clean inputs, the actual cost increase may be slower than the simulated data suggests.

Moreover, in our numerical model, we pursue a greenfield approach with all capacities endogenous. Results reflect the long-term elasticity between clean and dirty inputs. In contrast, adding clean capacities to an existing energy system with long-lived assets tends to be more difficult (Fouquet, 2016), and, in a shortrun perspective, the elasticity is likely lower (Mattauch et al., 2015; Pottier et al., 2014).

Concerning numerical assumptions, we rely on data for wind and solar energy based on a historical German technology park. On the one hand, the current energy yield per installed wind turbine or solar panel is likely higher than reflected in our input data (Staffell and Pfenninger, 2016). This may add to underestimating substitutability. On the other hand, our stylized scenarios assume no capacity limits for investments in clean technologies. While this helps to isolate the technological substitutability, expansion may be restricted in real-world settings. Additionally, if site quality worsens upon expansion of clean capacities, substitution becomes more difficult, especially for high shares of clean inputs.

\subsection{Implications for Macroeconomic Modeling}

Both the CES and VES production functions show a similar, and good, fit to the simulated data. This challenges the idea that the increasing difficulty in the substitution of clean for dirty inputs is best accommodated by a production function that allows for a decreasing elasticity of substitution, like the VES (cf. Wiskich, 2019). ${ }^{21}$ In fact, even for a constant elasticity, the exchange ratio between clean and dirty inputs in absolute terms, i.e., the marginal rate of technical substitution (MRTS), increases in the share of clean inputs.

While both production functions can replicate the rising difficulty of input substitution, our results indicate that the VES approach may rather overestimate this increase, while the CES approach rather underestimates it, albeit, in most cases, to a lower extent.

As the VES function neither provides a significantly better overall fit nor prediction performance, this favors using the more tractable CES function for electricity production within aggregate macroeconomic models. Particularly in computable general equilibrium (CGE) models, where the CES specification is

\footnotetext{
${ }^{21}$ See Growiec and Schumacher (2008) and Stöckl (2020) for CES-based macroeconomic models in which the elasticity of substitution can increase over time, either exogenously or due to investment in research.
} 
standard, our findings suggest that conveniently integrating electricity generation based on the CES specification is viable.

Yet, the limitations of the numerical model discussed above may understate or overstate the difficulty of substitution. An understated difficulty rather leans toward a VES approach; an overstated difficulty rather leans toward a CES approach. Any applied macroeconomic work must, thus, carefully evaluate its setting and boundaries. Our discussion sets forth the relevant mechanisms.

\subsection{Relation to Empirical Work}

In our numerical bottom-up model, we have full control of the data generating process. For simplicity, we assume constant costs and efficiencies of each clean and dirty input for all shares of clean energy. Thus, the fitted production functions allow for conveniently interpreting the elasticity of substitution as reflecting the technological difficulty in the transformation toward clean production. ${ }^{22}$

In contrast, when using observed data in empirical work, the substitution, cost-change, and efficiency channels cannot be easily disentangled. For instance, without further assumptions, the effect of increasing input costs cannot be disentangled from changes in costs due to more difficult substitution. ${ }^{23}$ Thus, an empirical specification may suffer from bias due to insufficient or wrong accounting for cost-changes or technological progress. ${ }^{24}$ As a consequence, the observed effective elasticity of substitution may overstate or understate the underlying technological elasticity of substitution. ${ }^{25}$ In any case, when comparing the results of our numerical optimization model to empirical results, these two elasticity concepts should not be mixed up.

\footnotetext{
${ }^{22}$ In principle, a numerical approach can also accommodate costs or efficiencies that change with increasing deployment of capacities or policy interventions. However, this requires special care when interpreting the fitted elasticity of substitution. We leave this avenue for future research.

${ }^{23}$ For instance, if costs in our numerical model linearly decrease in the shares of clean generation, from $+10 \%$ for $\iota=0$ to $-10 \%$ for $\iota=100$ the fitted elasticity in the CES specification is $\sigma=11.31$ (scenario $A l l_{ \pm 10 \%}$ in Table A.5), compared to $\sigma=6.46$ in scenario All.

${ }^{24}$ See, e.g., Diamond et al. (1978) for a discussion of the impossibility to identify both the elasticity and technological progress at the same time without further assumptions.

${ }^{25}$ Knoblach and Stöckl (2020) discuss the difference between the technological elasticity of substitution (EOS) and the observable effective elasticity of substitution (EES), which is usually estimated in empirical studies and also comprises institutional factors such as preferences for specific technologies.
} 


\section{Conclusion}

We derive production isoquants from a numerical bottom-up optimization model of electricity production. To this end, we vary the share of clean energy and fit CES and VES production functions to the simulated data. Central results show that (i) the elasticity of substitution between clean and dirty inputs is above unity as long as some energy storage is available. That is, dirty inputs are not essential for production; (ii) substitution is harder for higher shares of clean energy; and (iii) no single clean technology is indispensable for a complete shift to clean production but a balanced mix makes a transition easier. For high shares of clean inputs, in particular long-term storage facilitates substitution.

In relation to macroeconomic analysis, both the CES and VES production functions show a good fit to the simulated data. The CES approach is rather optimistic and tends to underestimate required clean inputs when extrapolating from low to high shares of clean generation; the VES approach rather underestimates it. For the CES approach, we show that technology availability can be readily accommodated by changing the elasticity parameter. In contrast to empirical analysis, we control the data-generating process and, thus, can separate technological substitutability from the effects of costs and efficiency on observed substitution. For costs, a sensitivity shows that lower costs of clean inputs mitigate the cost increase, yet leave the elasticity of substitution largely unaffected when relative costs within the clean aggregate do not change. Our results also show that estimation results based on data for lower shares of clean inputs observable today contain only limited information regarding future higher shares as the structure of energy supply changes.

While our numerical bottom-up model captures central aspects of clean energy supply, such as variability and storage, there is room for future research. A stylized model extension shows that future flexible electricity demand from other sectors, such as heating or further industrial processes, bears the potential to facilitate the substitution of clean for dirty inputs. A more detailed analysis must await another paper. Importantly, even if numerical assumptions and abstractions necessary for a forward-looking numerical model are well grounded, we refrain from taking specific numerical results on the elasticity at face value. Rather, we use the numerical model as a tool to lay out mechanisms that shape the substitutability between clean and dirty inputs in electricity production in general. 


\section{A Appendix}

\section{A.1 Reconciling the Empirical Results of Papageorgiou et al. (2017) with Our Findings}

Using clean and dirty generation capacities as input measure, we obtain nonconvex production isoquants for the data generated with our bottom-up optimization model (Section 4.1). In contrast, also using capacities, Papageorgiou et al. (2017) find a good fit of the convex CES function in an estimation of the cross-country elasticity of substitution based on panel data of 26 OECD countries. The following considerations may help to reconcile the differently shaped isoquants.

First, if restricted to lower shares of clean energy, also our data give rise to roughly convex isoquants (Figure 1), which only become non-convex for the full sample. Thus, the convexity found by Papageorgiou et al. (2017) may be driven by the fact that the share of clean capacities is below $50 \%$ for about two-thirds of all countries in their sample. However, it is not clear a priori that convexity is preserved if the share of clean inputs increases further for more countries.

Second, in the sample of Papageorgiou et al. (2017), the share of clean capacities varies substantially across countries, but hardly changes over time within most countries. Thus, the estimated 'synthetic' CES production function comprises several segments of clean shares. Each is represented by a different country, rather than capturing the rise of clean capacities for a specific country. This requires the assumption that the elasticity of substitution is constant not only for all shares of clean capacities within a country, but also across different countries. However, country idiosyncrasies cast doubts on the latter assumption. As such, it is not clear whether the substitution pattern for a country like Denmark, with good wind but modest solar and hydro storage resources along with an already high share of clean inputs, contains sufficient relevant information on an expected future substitution pattern for a country like Mexico, with good solar and hydro storage resources. Moreover, countries with a high elasticity of substitution may be those that also have a high share of clean inputs because substitution is easier for them.

Using a numerical model, production isoquants over the full range of possible shares of clean inputs can be retrieved for the same unique and time-invariant characteristics as observed for a specific country. 


\section{A.2 Numerical Assumptions for the Bottom-Up Model}

Table A.1 lists all assumptions for investment, fixed, and variable costs that enter the numerical model. Annualized investment costs for generation (Schröder et al., 2013) and storage (Pape et al., 2014; Schmidt et al., 2017; Welder et al., 2018) technologies are derived from overnight costs and the technical lifetime of the investment. Variable costs are derived from fuel costs and technical efficiency (Schill and Zerrahn, 2018; Schröder et al., 2013).

Table A.1: Cost Assumptions as Used in the Numerical Model

\begin{tabular}{|c|c|c|c|}
\hline \multicolumn{2}{|c|}{ Generation technologies } & \multirow{2}{*}{$\begin{array}{l}\text { Annualized investment and fixed costs }\left(\kappa^{i}\right) \\
{\left[\begin{array}{c}{[\mathrm{EUR} / \mathrm{MW}(\mathrm{h})]^{\mathrm{a}}} \\
66,264\end{array}\right.}\end{array}$} & \multirow{2}{*}{$\begin{array}{c}\begin{array}{c}\text { Variable costs }\left(\kappa^{v}\right) \\
{[\mathrm{EUR} / \mathrm{MWh}]}\end{array} \\
51.9\end{array}$} \\
\hline Natural gas & & & \\
\hline Wind onshore & & 110,662 & 0 \\
\hline Wind offshore & & 240,414 & 0 \\
\hline Photovoltaics & & 63,407 & 0 \\
\hline Bio energy & & 227,747 & 21.4 \\
\hline Run-of river hydro & & 192,606 & 0 \\
\hline \multicolumn{4}{|l|}{ Storage technologies } \\
\hline \multirow[t]{3}{*}{ Battery storage } & in & 14,399 & 0.3 \\
\hline & out $^{\mathrm{b}}$ & 0 & 0 \\
\hline & energy & 33,597 & 0 \\
\hline \multirow[t]{3}{*}{ Pumped-hydro storage } & in & 45,995 & 0.6 \\
\hline & out $^{\mathrm{b}}$ & 0 & 0 \\
\hline & energy & 418 & 0 \\
\hline \multirow[t]{3}{*}{ Power-to-gas storage } & in & 34,116 & 0 \\
\hline & out & 51,856 & 0.1 \\
\hline & energy & 35 & 0 \\
\hline
\end{tabular}

Note: Investment and fixed costs rounded to integers, variable costs rounded to one decimal.

a: Investment and fixed costs in general in EUR/MW, for storage energy investments in EUR/MWh.

b: For convenience, investment costs for battery and pumped-hydro storage power only attributed to storing in.

The efficiency parameters of the storages (not shown in the Table A.1) are $\vec{\eta}_{s t}=$ $\overleftarrow{\eta}_{s t}=0.97$ for batteries, $\vec{\eta}_{s t}=0.97$, and $\overleftarrow{\eta}_{s t}=0.91$ for pumped-hydro storage, and $\vec{\eta}_{s t}=0.70$ and $\overleftarrow{\eta}_{s t}=0.60$ for power-to-gas. The maximum storage duration, technically the energy-to-power ratio, is $\tau_{s t}=4$ for batteries, $\tau_{s t}=8$ for pumped-hydro storage, and unlimited for power-to-gas storage. These values 
are in line with both current standard configurations and a sweet spot in the trade-off between investment costs for power and energy capacities.

Using actual German data from the year 2016 (OPSD, 2018; Wiese et al., 2019), hourly electricity demand sums to $\sum_{h} d_{h}=479.9$ Terawatt hours per year. The capacity factors $\phi_{h, c l}$ of onshore wind, offshore wind, and solar photovoltaics are derived from re-analysis weather data from the base year 2016 (Pfenninger and Staffell, 2016; Staffell and Pfenninger, 2016). In line with a conservative approach, the resulting energy yield of solar and, in particular, wind power is pessimistic because (i) 2016 was a year with comparatively bad wind conditions; and (ii) the weather data is applied to the stock of wind and solar plants existing or approved by 2016. This stock contains a relevant proportion of old installations with low efficiency. Due to technological progress, the actual future energy yield is likely higher. The capacity factor of run-of-river hydro power, used in scenario Germany, is taken from Schill and Zerrahn (2018).

Table A.2 lists the capacity bounds for investments in scenario Germany. For all values, we follow rather pessimistic projections from established medium-term outlooks for Germany.

Table A.2: Capacity Limits in Scenario Germany

\begin{tabular}{|c|c|c|}
\hline Technology & Capacity limit & Source \\
\hline Natural gas & unlimited & \\
\hline Wind onshore & $80.7 \mathrm{GW}$ & UBA (2019) \\
\hline Wind offshore & $54.0 \mathrm{GW}$ & Fraunhofer-IWES (2013) \\
\hline Photovoltaics & $275.0 \mathrm{GW}$ & Fraunhofer-IWES (2013) \\
\hline Bio energy $^{a}$ & $8.3 \mathrm{GW}$ & BMWi (2020) \\
\hline Run-of river hydro ${ }^{a}$ & $5.6 \mathrm{GW}$ & BMWi (2020) \\
\hline Battery storage & unlimited & \\
\hline Pumped-hydro storage ${ }^{\mathrm{b}}$ & $11.8 \mathrm{GW}, 82.6 \mathrm{GWh}$ & Bundesnetzagentur (2018) \\
\hline Power-to-gas storage & unlimited & \\
\hline
\end{tabular}




\section{A.3 Formal Definition of Electricity System Costs}

Using the nomenclature of our numerical model, clean and dirty electricity system costs (in Euros) are given by:

$$
\begin{array}{r}
E S C_{\iota}^{\text {clean }}=\sum_{c l} \kappa_{c l}^{i} \tilde{N}_{c l}^{\iota}+\tilde{K}^{\iota}-(1-\iota) \tilde{K}^{0}, \\
E S C_{\iota}^{\text {dirty }}=\sum_{d i}\left(\kappa_{d i}^{i} \tilde{N}_{d i}+\sum_{h} \kappa_{d i}^{v} \tilde{G}_{h, d i}\right)+(1-\iota) \tilde{K}^{0},
\end{array}
$$

where a tilde indicates the optimal value from the numerical model for a clean energy share of $\iota$. They comprise annualized investment costs, annual fixed costs, and variable costs of generation and storage summed up over the year, the latter for convenience denoted as:

$$
\tilde{K}^{\iota} \equiv \sum_{s t}\left(\vec{\kappa}_{s t}^{i} \tilde{\vec{N}}_{s t}^{\iota}+\overleftarrow{\kappa}_{s t}^{i} \overleftarrow{\hat{N}}_{s t}^{\iota}+\kappa_{s t}^{i} \tilde{N}_{s t}^{\iota}+\sum_{h}\left(\vec{\kappa}_{s t}^{v} \tilde{\vec{S}}_{h, s t}^{\iota}+\overleftarrow{\kappa}_{v}^{i} \tilde{S}_{h, s t}^{\iota}\right)\right)
$$

For the small part of storage $\tilde{K}^{0}$ already built for a case without clean generation, costs are attributed to the dirty and clean ESC proportionate to the share of dirty and clean energy. Costs of any further storage that complements clean energy investment are attributed to the clean ESC.

\section{A.4 Fitting Results - Figures and Data Tables}

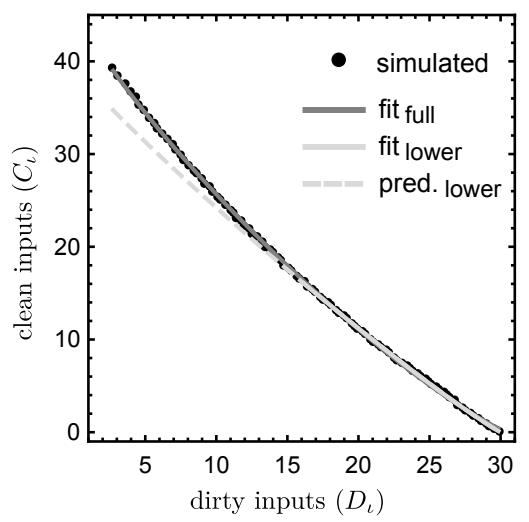

(a) CES

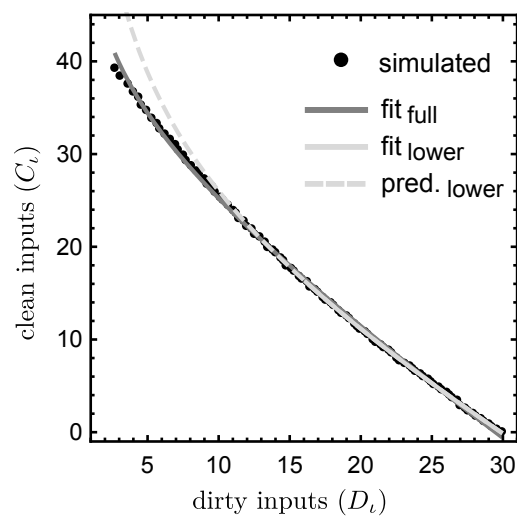

(b) VES

Figure A.1: Fitted Production Functions for the Full Sample and Predicted Production Functions Based on the Lower Sample - Scenario All 


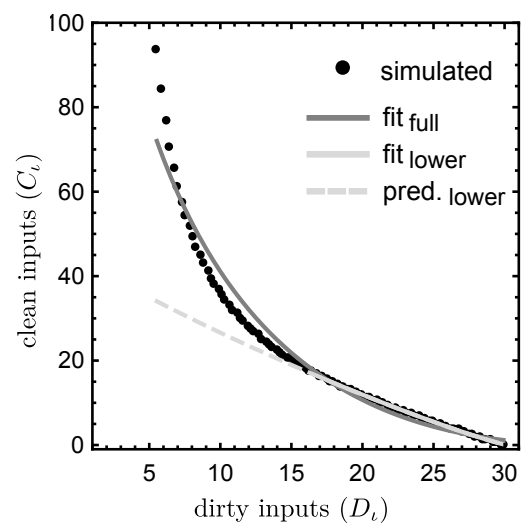

(a) CES

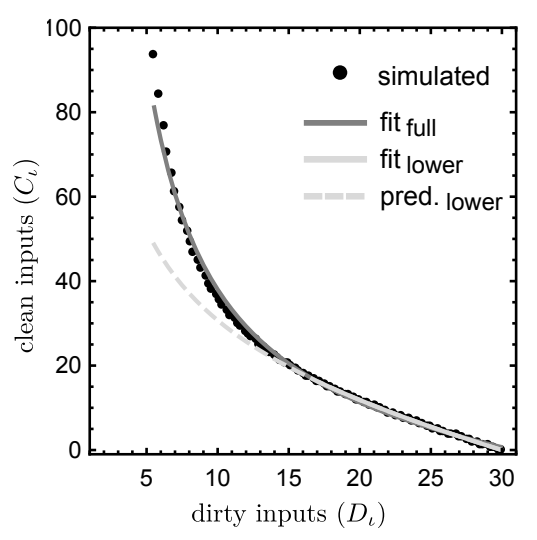

(b) VES

Figure A.2: Fitted Production Functions for the Full Sample and Predicted Production Functions Based on the Lower Sample - Scenario No sto

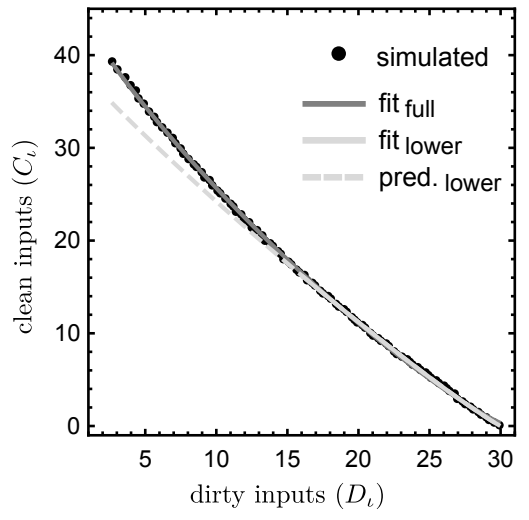

(a) CES

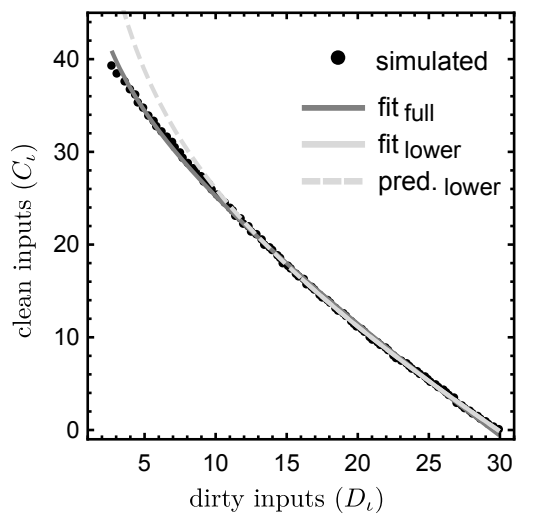

(b) VES

Figure A.3: Fitted Production Functions for the Full Sample and Predicted Production Functions Based on the Lower Sample - Scenario No bat

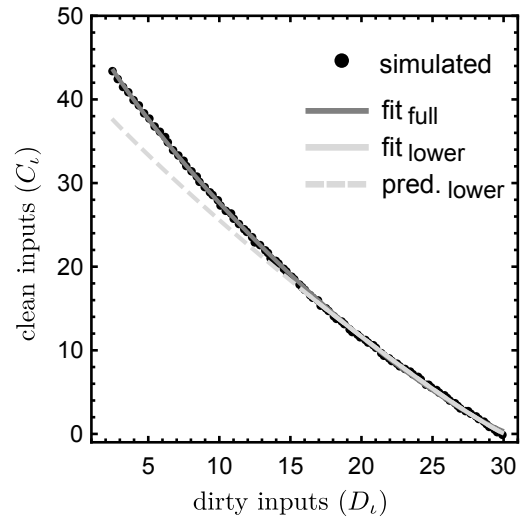

(a) CES

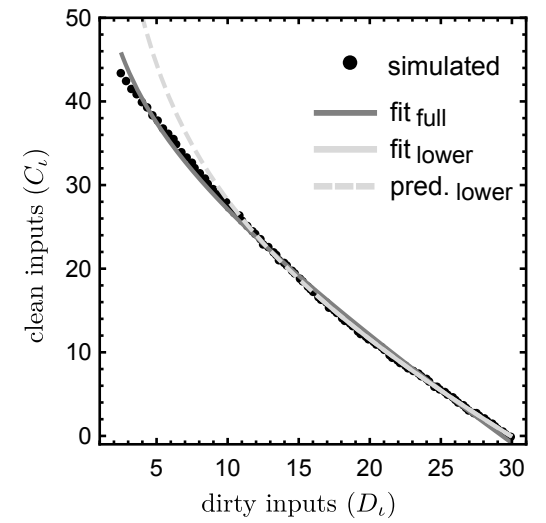

(b) VES

Figure A.4: Fitted Production Functions for the Full Sample and Predicted Production Functions Based on the Lower Sample - Scenario No phs 


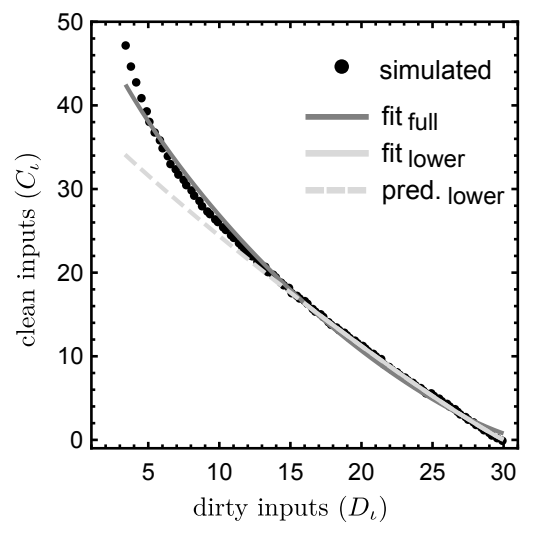

(a) CES

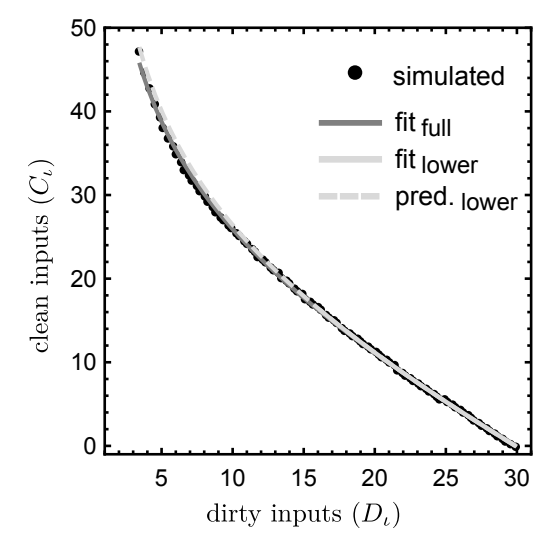

(b) VES

Figure A.5: Fitted Production Functions for the Full Sample and Predicted Production Functions Based on the Lower Sample - Scenario No p2g

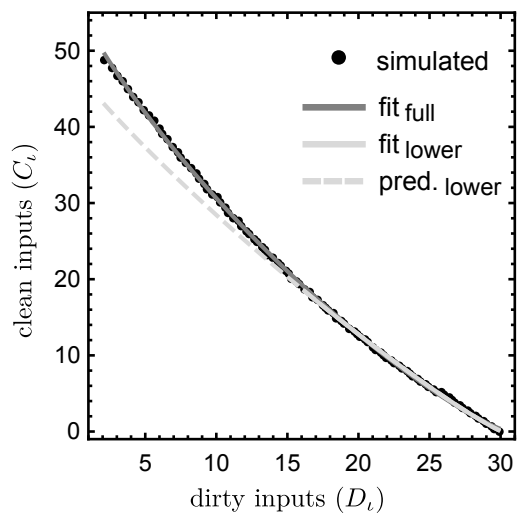

(a) CES

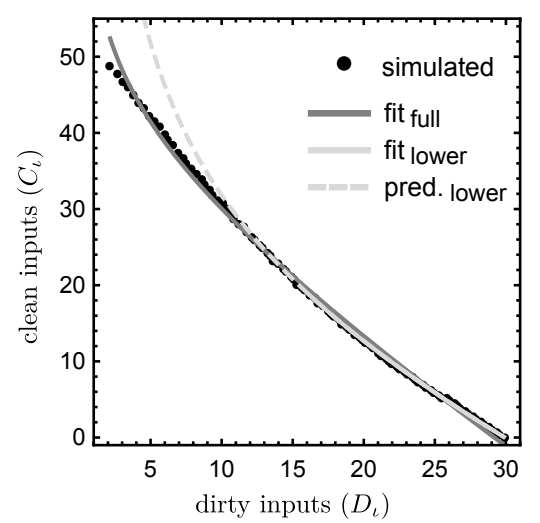

(b) VES

Figure A.6: Fitted Production Functions for the Full Sample and Predicted Production Functions Based on the Lower Sample - Scenario Wind only

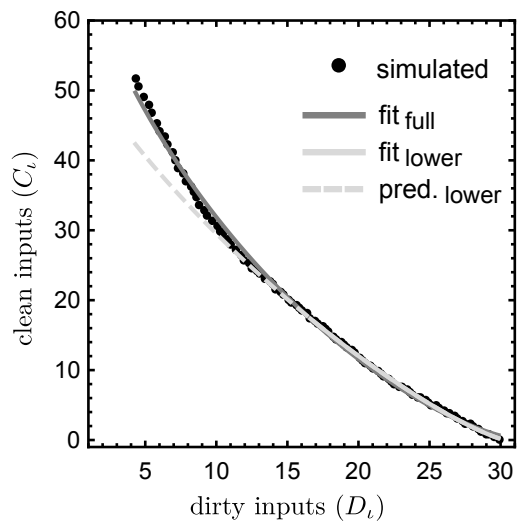

(a) CES

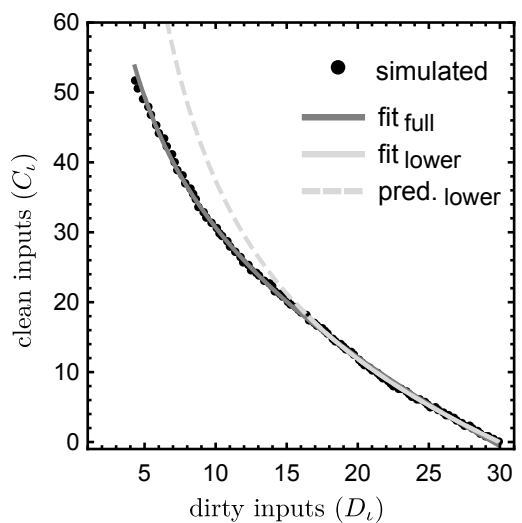

(b) VES

Figure A.7: Fitted Production Functions for the Full Sample and Predicted Production Functions Based on the Lower Sample - Scenario PV only 
Table A.3: Mean Squared Error (MSE) w.r.t. Output $(E)$ - in $\mathrm{MWh}^{2}$

(a) CES

\begin{tabular}{|c|c|c|c|c|}
\hline & full & lower & higher & higher $\left.\right|_{\text {lower }}$ \\
\hline Germany & $2.455 \cdot 10^{13}$ & $1.332 \cdot 10^{12}$ & $8.378 \cdot 10^{12}$ & $7.269 \cdot 10^{14}$ \\
\hline All & $4.798 \cdot 10^{12}$ & $6.331 \cdot 10^{11}$ & $1.799 \cdot 10^{10}$ & $6.849 \cdot 10^{14}$ \\
\hline No sto & $5.017 \cdot 10^{14}$ & $1.853 \cdot 10^{12}$ & $8.966 \cdot 10^{12}$ & $4.124 \cdot 10^{16}$ \\
\hline Nobat & $4.798 \cdot 10^{12}$ & $6.331 \cdot 10^{11}$ & $1.799 \cdot 10^{10}$ & $6.849 \cdot 10^{14}$ \\
\hline Nophs & $5.393 \cdot 10^{12}$ & $1.205 \cdot 10^{12}$ & $2.772 \cdot 10^{11}$ & $1.156 \cdot 10^{15}$ \\
\hline$N o p 2 g$ & $9.784 \cdot 10^{13}$ & $7.654 \cdot 10^{11}$ & $1.167 \cdot 10^{13}$ & $2.564 \cdot 10^{15}$ \\
\hline Wind only & $6.224 \cdot 10^{12}$ & $2.137 \cdot 10^{12}$ & $5.544 \cdot 10^{11}$ & $1.089 \cdot 10^{15}$ \\
\hline PV only & $4.637 \cdot 10^{13}$ & $5.625 \cdot 10^{12}$ & $2.108 \cdot 10^{12}$ & $1.152 \cdot 10^{15}$ \\
\hline$A l l_{-25 \%}$ & $5.345 \cdot 10^{12}$ & $6.403 \cdot 10^{11}$ & $1.542 \cdot 10^{10}$ & $6.995 \cdot 10^{14}$ \\
\hline$A l l_{-50 \%}$ & $5.666 \cdot 10^{12}$ & $7.052 \cdot 10^{11}$ & $1.566 \cdot 10^{10}$ & $7.125 \cdot 10^{14}$ \\
\hline No sto $_{-25 \%}$ & $5.015 \cdot 10^{14}$ & $1.860 \cdot 10^{12}$ & $8.950 \cdot 10^{12}$ & $4.121 \cdot 10^{16}$ \\
\hline No sto $_{-50 \%}$ & $5.023 \cdot 10^{14}$ & $1.827 \cdot 10^{12}$ & $8.891 \cdot 10^{12}$ & $4.155 \cdot 10^{16}$ \\
\hline $\operatorname{All}_{X_{10 \%}}$ & $5.668 \cdot 10^{12}$ & $5.037 \cdot 10^{11}$ & $4.424 \cdot 10^{11}$ & $5.119 \cdot 10^{14}$ \\
\hline$A l l_{X_{25 \%}}$ & $3.840 \cdot 10^{12}$ & $2.964 \cdot 10^{11}$ & $2.847 \cdot 10^{11}$ & $3.802 \cdot 10^{14}$ \\
\hline$A l l_{ \pm 10 \%}$ & $3.646 \cdot 10^{12}$ & $2.253 \cdot 10^{11}$ & $1.334 \cdot 10^{11}$ & $3.495 \cdot 10^{14}$ \\
\hline
\end{tabular}

Calculation: $\left(\left|\hat{Y}_{\iota}-Y_{\iota}\right|_{D_{\iota}, C_{\iota}}\right)^{2} / n$, where $\hat{Y}_{\iota}$ is predicted output of the fitted production function given $D_{\iota}$ and $C_{\iota} . n$ denotes the number of data points.

Note: higher| $\left.\right|_{\text {lower }}$ is the MSE of the higher sample based on the fitted parameters of the lower sample.

(b) VES

\begin{tabular}{lcccc}
\hline & full & lower & higher & higher $\left.\right|_{\text {lower }}$ \\
\hline Germany & $3.463 \cdot 10^{13}$ & $3.496 \cdot 10^{12}$ & $1.775 \cdot 10^{13}$ & $2.808 \cdot 10^{15}$ \\
All & $1.329 \cdot 10^{13}$ & $2.793 \cdot 10^{10}$ & $4.674 \cdot 10^{11}$ & $5.982 \cdot 10^{14}$ \\
No sto & $6.205 \cdot 10^{13}$ & $2.414 \cdot 10^{11}$ & $1.178 \cdot 10^{13}$ & $5.834 \cdot 10^{15}$ \\
Nobat & $1.329 \cdot 10^{13}$ & $2.793 \cdot 10^{10}$ & $4.674 \cdot 10^{11}$ & $5.991 \cdot 10^{14}$ \\
Nophs & $3.342 \cdot 10^{13}$ & $8.415 \cdot 10^{10}$ & $1.551 \cdot 10^{12}$ & $1.159 \cdot 10^{15}$ \\
Nop $2 g$ & $5.352 \cdot 10^{12}$ & $7.013 \cdot 10^{10}$ & $4.173 \cdot 10^{12}$ & $5.787 \cdot 10^{13}$ \\
Windonly $_{\text {PV only }}$ & $4.595 \cdot 10^{13}$ & $3.010 \cdot 10^{11}$ & $2.323 \cdot 10^{12}$ & $1.944 \cdot 10^{15}$ \\
All $25 \%$ & $1.027 \cdot 10^{13}$ & $1.346 \cdot 10^{12}$ & $5.849 \cdot 10^{12}$ & $2.960 \cdot 10^{15}$ \\
All & $1.316 \cdot 10^{13}$ & $2.276 \cdot 10^{10}$ & $7.008 \cdot 10^{11}$ & $5.663 \cdot 10^{14}$ \\
No sto $_{-25 \%}$ & $1.299 \cdot 10^{13}$ & $6.044 \cdot 10^{10}$ & $7.422 \cdot 10^{11}$ & $5.245 \cdot 10^{14}$ \\
No sto $_{-50 \%}$ & $6.200 \cdot 10^{13}$ & $2.415 \cdot 10^{11}$ & $1.175 \cdot 10^{13}$ & $5.816 \cdot 10^{15}$ \\
All $_{10 \%}$ & $6.233 \cdot 10^{13}$ & $2.642 \cdot 10^{11}$ & $1.167 \cdot 10^{13}$ & $6.085 \cdot 10^{15}$ \\
All $_{X_{25 \%}}$ & $5.508 \cdot 10^{12}$ & $5.190 \cdot 10^{10}$ & $1.552 \cdot 10^{11}$ & $2.773 \cdot 10^{14}$ \\
All $_{ \pm 10 \%}$ & $3.223 \cdot 10^{12}$ & $6.410 \cdot 10^{10}$ & $1.595 \cdot 10^{11}$ & $6.105 \cdot 10^{13}$ \\
\hline Calcution $^{13}$ & $2.056 \cdot 10^{12}$ & $8.000 \cdot 10^{10}$ & $3.762 \cdot 10^{10}$ & $9.753 \cdot 10^{12}$ \\
\hline
\end{tabular}

Calculation: $\left(\left|\hat{Y}_{\iota}-Y_{\iota}\right|_{D_{\iota}, C_{\iota}}\right)^{2} / n$, where $\hat{Y}_{\iota}$ is predicted output of the fitted production function given $D_{\iota}$ and $C_{\iota}$. n denotes the number of data points.

Note: higher $\left.\right|_{\text {lower }}$ is the MSE of the higher sample based on the fitted parameters of the lower sample. 
Table A.4: Average Gap Between Predicted and Required Clean Input - in bn $€$

(a) CES

\begin{tabular}{|c|c|c|c|c|}
\hline & full & lower & higher & higher| $\left.\right|_{\text {lower }}$ \\
\hline Germany & 0.296 & 0.049 & 0.221 & 1.464 \\
\hline All & 0.122 & 0.047 & 0.010 & 1.704 \\
\hline No sto & 2.317 & 0.080 & 0.527 & 11.854 \\
\hline Nobat & 0.122 & 0.047 & 0.010 & 1.704 \\
\hline Nophs & 0.137 & 0.064 & 0.043 & 2.445 \\
\hline No $p 2 g$ & 0.627 & 0.052 & 0.290 & 2.725 \\
\hline Wind only & 0.171 & 0.102 & 0.063 & 2.685 \\
\hline PV only & 0.539 & 0.148 & 0.152 & 2.421 \\
\hline$A l l_{-25 \%}$ & 0.099 & 0.036 & 0.006 & 1.287 \\
\hline$A l l_{-50 \%}$ & 0.069 & 0.026 & 0.004 & 0.870 \\
\hline No sto $_{-25 \%}$ & 1.738 & 0.060 & 0.394 & 8.889 \\
\hline No sto $_{-50 \%}$ & 1.160 & 0.040 & 0.262 & 5.939 \\
\hline$A l l_{X_{10 \%}}$ & 0.144 & 0.046 & 0.049 & 1.487 \\
\hline$A l l_{X_{25 \%}}$ & 0.127 & 0.039 & 0.034 & 1.400 \\
\hline$A l l_{ \pm 10 \%}$ & 0.111 & 0.030 & 0.025 & 1.118 \\
\hline
\end{tabular}

Calculation: $\left(\left|\hat{C}_{\iota}-C_{\iota}\right|_{Y_{\iota}, D_{\iota}}\right) / n$, where $\hat{C}_{\iota}$ is predicted required clean input of the fitted production function given $Y_{\iota}$ and $D_{\iota} . n$ denotes the number of data points.

Note: higher| $\left.\right|_{\text {lower }}$ is the average gap of the higher sample based on the fitted parameters of the lower sample.

\section{(b) VES}

\begin{tabular}{|c|c|c|c|c|}
\hline & full & lower & higher & higher| $\left.\right|_{\text {lower }}$ \\
\hline Germany & 0.350 & 0.098 & 0.324 & 6.115 \\
\hline All & 0.257 & 0.010 & 0.052 & 1.755 \\
\hline No sto & 0.970 & 0.031 & 0.625 & 7.720 \\
\hline Nobat & 0.257 & 0.010 & 0.052 & 1.757 \\
\hline Nophs & 0.441 & 0.018 & 0.104 & 2.959 \\
\hline$N o p 2 g$ & 0.151 & 0.017 & 0.177 & 0.679 \\
\hline Wind only & 0.572 & 0.040 & 0.140 & 4.832 \\
\hline PV only & 0.253 & 0.082 & 0.254 & 9.928 \\
\hline$A l l_{-25 \%}$ & 0.191 & 0.006 & 0.048 & 1.281 \\
\hline$A l l_{-50 \%}$ & 0.126 & 0.008 & 0.032 & 0.817 \\
\hline No sto $_{-25 \%}$ & 0.727 & 0.024 & 0.469 & 5.784 \\
\hline No sto $_{-50 \%}$ & 0.486 & 0.017 & 0.311 & 3.912 \\
\hline$A l l_{X_{10 \%}}$ & 0.169 & 0.016 & 0.027 & 1.116 \\
\hline$A l l_{X_{25 \%}}$ & 0.140 & 0.019 & 0.033 & 0.484 \\
\hline$A l l_{ \pm 10 \%}$ & 0.096 & 0.017 & 0.013 & 0.224 \\
\hline
\end{tabular}

Calculation: $\left(\left|\hat{C}_{\iota}-C_{\iota}\right|_{Y_{\iota}, D_{\iota}}\right) / n$, where $\hat{C}_{\iota}$ is predicted required clean input of the fitted production function given $Y_{\iota}$ and $D_{\iota} . n$ denotes the number of data points.

Note: higher| $\left.\right|_{\text {lower }}$ is the average gap of the higher sample based on the fitted parameters of the lower sample. 
Table A.5: All Fitted Parameters of the CES and VES Production Functions

\begin{tabular}{|c|c|c|c|c|c|c|}
\hline & \multicolumn{3}{|c|}{$\mathrm{CES}$} & \multicolumn{3}{|c|}{ VES } \\
\hline & full & lower & higher & full & lower & higher \\
\hline Germany & $\begin{array}{l}A=0.032 \\
\alpha=0.413 \\
\sigma=3.94\end{array}$ & $\begin{array}{l}A=0.032 \\
\alpha=0.437 \\
\sigma=6.13\end{array}$ & $\begin{array}{l}A=0.032 \\
\alpha=0.416 \\
\sigma=3.25\end{array}$ & $\begin{aligned} A & =0.021 \\
a & =0.235 \\
b & =3.160 \\
\bar{\sigma} & >1000 \\
\underline{\sigma} & =1.22\end{aligned}$ & $\begin{aligned} A & =0.025 \\
a & =0.413 \\
b & =1.153 \\
\bar{\sigma} & >1000 \\
\underline{\sigma} & =2.29\end{aligned}$ & $\begin{aligned} A & =0.016 \\
a & =0.145 \\
b & =8.207 \\
\bar{\sigma} & =9.79 \\
\underline{\sigma} & =1.58\end{aligned}$ \\
\hline MSE: & $2.455 \cdot 10^{13}$ & $1.332 \cdot 10^{12}$ & $8.378 \cdot 10^{12}$ & $3.463 \cdot 10^{13}$ & $3.496 \cdot 10^{12}$ & $1.775 \cdot 10^{13}$ \\
\hline All & $\begin{array}{l}A=0.030 \\
\alpha=0.414 \\
\sigma=6.46\end{array}$ & $\begin{array}{l}A=0.030 \\
\alpha=0.438 \\
\sigma=13.32\end{array}$ & $\begin{array}{l}A=0.030 \\
\alpha=0.416 \\
\sigma=5.66\end{array}$ & $\begin{aligned} A & =0.016 \\
a & =0.138 \\
b & =7.279 \\
\bar{\sigma} & >1000 \\
\underline{\sigma} & =1.51\end{aligned}$ & $\begin{aligned} A & =0.019 \\
a & =0.250 \\
b & =3.153 \\
\bar{\sigma} & >1000 \\
\underline{\sigma} & =4.14\end{aligned}$ & $\begin{aligned} A & =0.014 \\
a & =0.076 \\
b & =17.336 \\
\bar{\sigma} & =17.61 \\
\underline{\sigma} & =2.21\end{aligned}$ \\
\hline MSE: & $4.798 \cdot 10^{12}$ & $6.331 \cdot 10^{11}$ & $1.799 \cdot 10^{10}$ & $1.329 \cdot 10^{13}$ & $2.793 \cdot 10^{10}$ & $4.674 \cdot 10^{11}$ \\
\hline No sto & $\begin{array}{l}A=0.028 \\
\alpha=0.298 \\
\sigma=1.84\end{array}$ & $\begin{array}{l}A=0.029 \\
\alpha=0.412 \\
\sigma=9.09\end{array}$ & $\begin{array}{l}A=0.028 \\
\alpha=0.423 \\
\sigma=0.94\end{array}$ & $\begin{aligned} A & =0.025 \\
a & =0.539 \\
b & =0.670 \\
\bar{\sigma} & >1000 \\
\underline{\sigma} & =1.04\end{aligned}$ & $\begin{aligned} A & =0.021 \\
a & =0.362 \\
b & =1.845 \\
\bar{\sigma} & >1000 \\
\underline{\sigma} & =2.97\end{aligned}$ & $\begin{aligned} A & =0.029 \\
a & =0.606 \\
b & =-0.118 \\
\bar{\sigma} & =0.88 \\
\underline{\sigma} & =0.99\end{aligned}$ \\
\hline MSE: & $5.017 \cdot 10^{14}$ & $1.853 \cdot 10^{12}$ & $8.966 \cdot 10^{12}$ & $6.205 \cdot 10^{13}$ & $2.414 \cdot 10^{11}$ & $1.178 \cdot 10^{13}$ \\
\hline No bat & $\begin{array}{l}A=0.030 \\
\alpha=0.414 \\
\sigma=6.46\end{array}$ & $\begin{array}{l}A=0.030 \\
\alpha=0.438 \\
\sigma=13.32\end{array}$ & $\begin{array}{l}A=0.030 \\
\alpha=0.416 \\
\sigma=5.66\end{array}$ & $\begin{aligned} A & =0.016 \\
a & =0.138 \\
b & =7.280 \\
\bar{\sigma} & >1000 \\
\underline{\sigma} & =1.51\end{aligned}$ & $\begin{aligned} A & =0.019 \\
a & =0.250 \\
b & =3.152 \\
\bar{\sigma} & >1000 \\
\underline{\sigma} & =4.14\end{aligned}$ & $\begin{aligned} A & =0.014 \\
a & =0.076 \\
b & =17.341 \\
\bar{\sigma} & =17.62 \\
\underline{\sigma} & =2.21\end{aligned}$ \\
\hline MSE: & $4.798 \cdot 10^{12}$ & $6.331 \cdot 10^{11}$ & $1.799 \cdot 10^{10}$ & $1.329 \cdot 10^{13}$ & $2.793 \cdot 10^{10}$ & $4.674 \cdot 10^{11}$ \\
\hline Nophs & $\begin{aligned} A & =0.029 \\
\alpha & =0.395 \\
\sigma & =5.57\end{aligned}$ & $\begin{array}{l}A=0.029 \\
\alpha=0.423 \\
\sigma=10.68\end{array}$ & $\begin{array}{l}A=0.029 \\
\alpha=0.384 \\
\sigma=6.67\end{array}$ & $\begin{array}{l}A=0.016 \\
a=0.154 \\
b=6.861 \\
\bar{\sigma}>1000 \\
\underline{\sigma}=1.40\end{array}$ & $\begin{aligned} A & =0.020 \\
a & =0.303 \\
b & =2.441 \\
\bar{\sigma} & >1000 \\
\underline{\sigma} & =3.38\end{aligned}$ & $\begin{aligned} A & =0.012 \\
a & =0.064 \\
b & =24.102 \\
\bar{\sigma} & =23.60 \\
\underline{\sigma} & =2.42\end{aligned}$ \\
\hline MSE: & $5.393 \cdot 10^{12}$ & $1.205 \cdot 10^{12}$ & $2.772 \cdot 10^{11}$ & $3.342 \cdot 10^{13}$ & $8.415 \cdot 10^{10}$ & $1.551 \cdot 10^{12}$ \\
\hline No $p 2 g$ & $\begin{aligned} A & =0.030 \\
\alpha & =0.395 \\
\sigma & =3.88\end{aligned}$ & $\begin{array}{l}A=0.030 \\
\alpha=0.435 \\
\sigma=12.38\end{array}$ & $\begin{aligned} A & =0.029 \\
\alpha & =0.484 \\
\sigma & =1.60\end{aligned}$ & $\begin{aligned} A & =0.019 \\
a & =0.255 \\
b & =3.031 \\
\bar{\sigma} & =>1000 \\
\underline{\sigma} & =1.22\end{aligned}$ & $\begin{aligned} A & =0.020 \\
a & =0.267 \\
b & =2.862 \\
\bar{\sigma} & >1000 \\
\underline{\sigma} & =3.88\end{aligned}$ & $\begin{aligned} A & =0.021 \\
a & =0.287 \\
b & =2.066 \\
\bar{\sigma} & =2.99 \\
\underline{\sigma} & =1.15\end{aligned}$ \\
\hline MSE: & $9.784 \cdot 10^{13}$ & $7.654 \cdot 10^{11}$ & $1.167 \cdot 10^{13}$ & $5.352 \cdot 10^{12}$ & $7.013 \cdot 10^{10}$ & $4.173 \cdot 10^{12}$ \\
\hline Wind only & $\begin{array}{l}A=0.028 \\
\alpha=0.374 \\
\sigma=5.44\end{array}$ & $\begin{array}{l}A=0.028 \\
\alpha=0.397 \\
\sigma=9.47\end{array}$ & $\begin{array}{l}A=0.028 \\
\alpha=0.355 \\
\sigma=7.51\end{array}$ & $\begin{aligned} A & =0.014 \\
a & =0.149 \\
b & =7.971 \\
\bar{\sigma} & >1000 \\
\underline{\sigma} & =1.35\end{aligned}$ & $\begin{aligned} A & =0.019 \\
a & =0.331 \\
b & =2.322 \\
\bar{\sigma} & >1000 \\
\underline{\sigma} & =3.01\end{aligned}$ & $\begin{aligned} A & =0.011 \\
a & =0.053 \\
b & =34.266 \\
\bar{\sigma} & =29.39 \\
\underline{\sigma} & =2.51\end{aligned}$ \\
\hline MSE: & $6.224 \cdot 10^{12}$ & $2.137 \cdot 10^{12}$ & $5.544 \cdot 10^{11}$ & $4.595 \cdot 10^{13}$ & $3.010 \cdot 10^{11}$ & $2.323 \cdot 10^{12}$ \\
\hline$P V$ only & $\begin{aligned} A & =0.028 \\
\alpha & =0.354 \\
\sigma & =3.28\end{aligned}$ & $\begin{aligned} A & =0.028 \\
\alpha & =0.378 \\
\sigma & =5.29\end{aligned}$ & $\begin{aligned} A & =0.028 \\
\alpha & =0.412 \\
\sigma & =1.82\end{aligned}$ & $\begin{aligned} A & =0.019 \\
a & =0.318 \\
b & =2.482 \\
\bar{\sigma} & >1000 \\
\underline{\sigma} & =1.21\end{aligned}$ & $\begin{aligned} A & =0.023 \\
a & =0.491 \\
b & =0.997 \\
\bar{\sigma} & >1000 \\
\underline{\sigma} & =1.95\end{aligned}$ & $\begin{aligned} A & =0.019 \\
a & =0.304 \\
b & =2.795 \\
\bar{\sigma} & =3.54 \\
\underline{\sigma} & =1.23\end{aligned}$ \\
\hline MSE: & $4.637 \cdot 10^{13}$ & $5.625 \cdot 10^{12}$ & $2.108 \cdot 10^{12}$ & $1.027 \cdot 10^{13}$ & $1.346 \cdot 10^{12}$ & $5.849 \cdot 10^{12}$ \\
\hline
\end{tabular}

Continued on next page 
Continued from previous page (Table A.5)

\begin{tabular}{|c|c|c|c|c|c|c|}
\hline & \multicolumn{3}{|c|}{ CES } & \multicolumn{3}{|c|}{ VES } \\
\hline & full & lower & higher & full & lower & higher \\
\hline$A l l_{-25 \%}$ & $\begin{aligned} A & =0.034 \\
\alpha & =0.473 \\
\sigma & =6.40\end{aligned}$ & $\begin{array}{l}A=0.034 \\
\alpha=0.503 \\
\sigma=13.40\end{array}$ & $\begin{array}{l}A=0.034 \\
\alpha=0.473 \\
\sigma=5.59\end{array}$ & $\begin{aligned} A & =0.021 \\
a & =0.140 \\
b & =5.392 \\
\bar{\sigma} & >1000 \\
\underline{\sigma} & =1.50\end{aligned}$ & $\begin{aligned} A & =0.024 \\
a & =0.248 \\
b & =2.401 \\
\bar{\sigma} & >1000 \\
\underline{\sigma} & =4.15\end{aligned}$ & $\begin{aligned} A & =0.018 \\
a & =0.076 \\
b & =13.039 \\
\bar{\sigma} & =17.40 \\
\underline{\sigma} & =2.21\end{aligned}$ \\
\hline MSE: & $5.345 \cdot 10^{12}$ & $6.403 \cdot 10^{11}$ & $1.542 \cdot 10^{10}$ & $1.316 \cdot 10^{13}$ & $2.276 \cdot 10^{10}$ & $7.008 \cdot 10^{11}$ \\
\hline$A l l_{-50 \%}$ & $\begin{array}{l}A=0.042 \\
\alpha=0.558 \\
\sigma=6.44\end{array}$ & $\begin{array}{l}A=0.043 \\
\alpha=0.595 \\
\sigma=13.61\end{array}$ & $\begin{array}{l}A=0.042 \\
\alpha=0.555 \\
\sigma=5.57\end{array}$ & $\begin{aligned} A & =0.029 \\
a & =0.140 \\
b & =3.611 \\
\bar{\sigma} & >1000 \\
\underline{\sigma} & =1.50\end{aligned}$ & $\begin{aligned} A & =0.032 \\
a & =0.244 \\
b & =1.650 \\
\bar{\sigma} & >1000 \\
\underline{\sigma} & =4.19\end{aligned}$ & $\begin{aligned} A & =0.026 \\
a & =0.076 \\
b & =8.772 \\
\bar{\sigma} & =17.28 \\
\underline{\sigma} & =2.21\end{aligned}$ \\
\hline MSE: & $5.666 \cdot 10^{12}$ & $7.052 \cdot 10^{11}$ & $1.566 \cdot 10^{10}$ & $1.299 \cdot 10^{13}$ & $6.044 \cdot 10^{10}$ & $7.422 \cdot 10^{11}$ \\
\hline No sto $_{-25 \%}$ & $\begin{array}{l}A=0.031 \\
\alpha=0.326 \\
\sigma=1.84\end{array}$ & $\begin{array}{l}A=0.033 \\
\alpha=0.475 \\
\sigma=9.08\end{array}$ & $\begin{array}{l}A=0.032 \\
\alpha=0.419 \\
\sigma=0.94\end{array}$ & $\begin{aligned} A & =0.028 \\
a & =0.539 \\
b & =0.503 \\
\bar{\sigma} & >1000 \\
\underline{\sigma} & =1.04\end{aligned}$ & $\begin{aligned} A & =0.025 \\
a & =0.362 \\
b & =1.382 \\
\bar{\sigma} & >1000 \\
\underline{\sigma} & =2.96\end{aligned}$ & $\begin{aligned} A & =0.033 \\
a & =0.606 \\
b & =-0.088 \\
\bar{\sigma} & =0.88 \\
\underline{\sigma} & =0.99\end{aligned}$ \\
\hline MSE: & $5.015 \cdot 10^{14}$ & $1.860 \cdot 10^{12}$ & $8.950 \cdot 10^{12}$ & $6.200 \cdot 10^{13}$ & $2.415 \cdot 10^{11}$ & $1.175 \cdot 10^{13}$ \\
\hline No sto $_{-50 \%}$ & $\begin{array}{l}A=0.036 \\
\alpha=0.368 \\
\sigma=1.84\end{array}$ & $\begin{array}{l}A=0.041 \\
\alpha=0.565 \\
\sigma=9.20\end{array}$ & $\begin{array}{l}A=0.038 \\
\alpha=0.413 \\
\sigma=0.94\end{array}$ & $\begin{aligned} A & =0.034 \\
a & =0.539 \\
b & =0.336 \\
\bar{\sigma} & >1000 \\
\underline{\sigma} & =1.04\end{aligned}$ & $\begin{aligned} A & =0.032 \\
a & =0.359 \\
b & =0.939 \\
\bar{\sigma} & >1000 \\
\underline{\sigma} & =3.00\end{aligned}$ & $\begin{aligned} A & =0.038 \\
a & =0.606 \\
b & =-0.059 \\
\bar{\sigma} & =0.88 \\
\underline{\sigma} & =0.99\end{aligned}$ \\
\hline MSE: & $5.023 \cdot 10^{14}$ & $1.827 \cdot 10^{12}$ & $8.891 \cdot 10^{12}$ & $6.233 \cdot 10^{13}$ & $2.642 \cdot 10^{11}$ & $1.167 \cdot 10^{13}$ \\
\hline$A l l_{X} 10 \%$ & $\begin{array}{l}A=0.028 \\
\alpha=0.428 \\
\sigma=7.58\end{array}$ & $\begin{array}{l}A=0.028 \\
\alpha=0.449 \\
\sigma=17.87\end{array}$ & $\begin{aligned} A & =0.028 \\
\alpha & =0.438 \\
\sigma & =5.25\end{aligned}$ & $\begin{aligned} A & =0.015 \\
a & =0.120 \\
b & =8.316 \\
\bar{\sigma} & >1000 \\
\underline{\sigma} & =1.61\end{aligned}$ & $\begin{aligned} A & =0.017 \\
a & =0.198 \\
b & =4.274 \\
\bar{\sigma} & >1000 \\
\underline{\sigma} & =5.31\end{aligned}$ & $\begin{aligned} A & =0.014 \\
a & =0.079 \\
b & =14.921 \\
\bar{\sigma} & =15.45 \\
\underline{\sigma} & =2.10\end{aligned}$ \\
\hline MSE: & $5.668 \cdot 10^{12}$ & $5.037 \cdot 10^{11}$ & $4.424 \cdot 10^{11}$ & $5.508 \cdot 10^{12}$ & $5.190 \cdot 10^{10}$ & $1.552 \cdot 10^{11}$ \\
\hline$A l l_{X_{25 \%}}$ & $\begin{aligned} A & =0.025 \\
\alpha & =0.440 \\
\sigma & =9.71\end{aligned}$ & $\begin{array}{l}A=0.025 \\
\alpha=0.459 \\
\sigma=27.47\end{array}$ & $\begin{array}{l}A=0.025 \\
\alpha=0.448 \\
\sigma=6.54\end{array}$ & $\begin{aligned} A & =0.013 \\
a & =0.094 \\
b & =10.800 \\
\bar{\sigma} & >1000 \\
\underline{\sigma} & =1.85\end{aligned}$ & $\begin{aligned} A & =0.014 \\
a & =0.137 \\
b & =6.739 \\
\bar{\sigma} & >1000 \\
\underline{\sigma} & =7.82\end{aligned}$ & $\begin{aligned} A & =0.012 \\
a & =0.062 \\
b & =18.792 \\
\bar{\sigma} & =19.24 \\
\underline{\sigma} & =2.48\end{aligned}$ \\
\hline MSE: & $3.840 \cdot 10^{12}$ & $2.964 \cdot 10^{11}$ & $2.847 \cdot 10^{11}$ & $3.223 \cdot 10^{12}$ & $6.410 \cdot 10^{10}$ & $1.595 \cdot 10^{11}$ \\
\hline$A l l_{ \pm 10 \%}$ & $\begin{array}{l}A=0.030 \\
\alpha=0.436 \\
\sigma=11.31\end{array}$ & $\begin{array}{l}A=0.030 \\
\alpha=0.454 \\
\sigma=46.01\end{array}$ & $\begin{array}{l}A=0.030 \\
\alpha=0.443 \\
\sigma=7.50\end{array}$ & $\begin{aligned} A & =0.015 \\
a & =0.081 \\
b & =13.130 \\
\bar{\sigma} & >1000 \\
\underline{\sigma} & =2.00\end{aligned}$ & $\begin{aligned} A & =0.016 \\
a & =0.093 \\
b & =10.978 \\
\bar{\sigma} & >1000 \\
\underline{\sigma} & =11.96\end{aligned}$ & $\begin{aligned} A & =0.014 \\
a & =0.053 \\
b & =22.485 \\
\bar{\sigma} & =22.62 \\
\underline{\sigma} & =2.72\end{aligned}$ \\
\hline MSE: & $3.646 \cdot 10^{12}$ & $2.253 \cdot 10^{11}$ & $1.334 \cdot 10^{11}$ & $2.056 \cdot 10^{12}$ & $8.000 \cdot 10^{10}$ & $3.762 \cdot 10^{10}$ \\
\hline
\end{tabular}

Abbreviations: MSE: Mean Squared Error; $\bar{\sigma}:=\sigma_{c^{\min }}, \underline{\sigma}:=\sigma_{c_{L} \max }$, where $c_{\iota}^{\min }$ and $c_{\iota}^{\max }$ denote the minimum and maximum share of clean inputs within the sample. 


\section{References}

Acemoglu, D., Aghion, P., Bursztyn, L., and Hemous, D. (2012). The Environment and Directed Technical Change. American Economic Review, 102(1):131-166.

Arrow, K. J., Chenery, H. B., Minhas, B. S., and Solow, R. M. (1961). CapitalLabor Substitution and Economic Efficiency. The Review of Economics and Statistics, 43(3):225-250.

BMWi (2020). Time Series for the Development of Renewable Energy Sources in Germany. Bundesministerium für Wirtschaft und Energie. Available at: https://www.erneuerbare-energien.de/EE/Navigation/DE/Service/ Erneuerbare_Energien_in_Zahlen/Zeitreihen/zeitreihen.html [last accessed: May 20, 2020].

Bodkin, R. G. and Klein, L. R. (1967). Nonlinear Estimation of Aggregate Production Functions. The Review of Economic and Statistics, 49(1):28-44.

Bretschger, L. (2005). Economics of Technological Change and the Natural Environment: How Effective are Innovations as a Remedy for Resource Scarcity? Ecological Economics, 54(2):148-163.

Brown, T., Schlachtberger, D., Kies, A., Schramm, S., and Greiner, M. (2018). Synergies of Sector Coupling and Transmission Reinforcement in a CostOptimised, Highly Renewable European Energy System. Energy, 160:720-739.

Bundesnetzagentur (2018). Genehmigung des Szenariorahmens 2019-2030. Available at: https://www.netzentwicklungsplan.de/sites/default/files/ paragraphs-files/Szenariorahmen_2019-2030_Genehmigung_0_0.pdf [last accessed: Apr. 6, 2020].

Diamond, P., McFadden, D., and Rodriguez, M. (1978). Measurement of the Elasticity of Substitution and Bias of Technical Change. In Fuss, M. and McFadden, D., editors, Production Economics: A Dual Approach to Theory and Applications, volume 2, chapter 5, pages 125-147. North-Holland, Amsterdam.

Fouquet, R. (2016). Path Dependence in Energy Systems and Economic Development. Nature Energy, 1(16098).

Fraunhofer-IWES (2013). Energiewirtschaftliche Bedeutung der Offshore-Windenergie für die Energiewende. Available at: https: 
//www.fraunhofer.de/content/dam/zv/de/forschungsthemen/energie/ Energiewirtschaftliche-Bedeutung-von-Off shore-Windenergie.pdf [last accessed: Apr. 15, 2020].

Greaker, M., Heggedal, T.-R., and Rosendahl, K. E. (2018). Environmental Policy and the Direction of Technical Change. The Scandinavian Journal of Economics, 120(4):1100-1138.

Growiec, J. and Mućk, J. (2019). Isoelastic Elasticity of Substitution Production Functions. Macroeconomic Dynamics. Advance Online Publication. https: //doi .org/10.1017/S1365100518000950.

Growiec, J. and Schumacher, I. (2008). On Technical Change in the Elasticities of Resource Inputs. Resources Policy, 33(4):210-221.

Hémous, D. (2016). The Dynamic Impact of Unilateral Environmental Policies. Journal of International Economics, 103:80-95.

IEA (2019a). Global Energy \& CO2 Status Report 2019. International Energy Agency (IEA), Paris. Available at: https://www.iea.org/reports/ global-energy-co2-status-report-2019 [last accessed: Apr. 15, 2020].

IEA (2019b). World Energy Outlook 2019. International Energy Agency (IEA), Paris. Available at: https://www.iea.org/reports/ world-energy-outlook-2019 [last accessed: May 20, 2020].

IPCC (2014). Climate Change 2014: Synthesis Report. Contribution of Working Groups I, II and III to the Fifth Assessment Report of the Intergovernmental Panel on Climate Change. Core Writing Team, R.K. Pachauri and L.A. Meyer (eds.). IPCC, Geneva, Switzerland.

Karagiannis, G., Palivos, T., and Papageorgiou, C. (2005). Variable Elasticity of Substitution and Economic Growth: Theory and Evidence. In Diebolt, C. and Kyrtsou, C., editors, New Trends in Macroeconomics, pages 21-37. Springer, Berlin, Heidelberg, New York.

Kemfert, C. (1998). Estimated Substitution Elasticities of a Nested CES Production Function Approach for Germany. Energy Economics, 20(3):249-264.

Klump, R., McAdam, P., and Willman, A. (2012). The Normalized CES Production Function: Theory and Empirics. Journal of Economic Surveys, 26(5):769799. 
Knoblach, M. and Stöckl, F. (2020). What Determines the Elasticity of Substitution Between Capital and Labor? A Literature Review. Journal of Economic Surveys. Advance Online Publication. https://doi.org/10.1111/ joes. 12366 .

Koetse, M. J., de Groot, H. L. F., and Florax, R. J. G. M. (2008). CapitalEnergy Substitution and Shifts in Factor Demand: A Meta-Analysis. Energy Economics, 30(5):2236-2251.

Kwon, P. and Østergaard, P. (2014). Assessment and Evaluation of Flexible Demand in a Danish Future Energy Scenario. Applied Energy, 134:309-320.

Malikov, E., Sun, K., and Kumbhakar, S. C. (2018). Nonparametric Estimates of the Clean and Dirty Energy Substitutability. Economics Letters, 168:118-122.

Mattauch, L., Creutzig, F., and Edenhofer, O. (2015). Avoiding Carbon LockIn: Policy Options for Advancing Structural Change. Economic Modelling, 50:49-63.

Meran, G. (2019). Thermodynamic Constraints and the Use of EnergyDependent CES-Production Functions A Cautionary Comment. Energy Economics, 81:63-69.

OPSD (2018). Data Package Time Series. Version 2018-03-13. Available at: https://data.open-power-system-data.org/time_series/2018-03-13 [last accessed: May 20, 2020].

Papageorgiou, C., Saam, M., and Schulte, P. (2017). Substitution Between Clean and Dirty Energy Inputs - A Macroeconomic Perspective. Review of Economics and Statistics, 99(2):281-290.

Pape, C., Gerhardt, N., Härtel, Scholz, P. A., Schwinn, R.and Drees, T., Maaz, A., Sprey, J., Breuer, C., Moser, A., Sailer, F., Reuter, S., and Müller, T. (2014). Roadmap Speicher. Commissioned by: BMWi Bundesministerium für Wirtschaft und Energie. Available at: https: //www.iee.fraunhofer.de/content/dam/iee/energiesystemtechnik/de/ Dokumente/Studien-Reports/2014_Roadmap-Speicher-Langfassung.pdf [last accessed: Apr. 6, 2020].

Pfenninger, S. (2017). Energy Scientists Must Show Their Workings. Nature, $542(393)$. 
Pfenninger, S. and Staffell, I. (2016). Long-Term Patterns of European PV Output Using 30 Years of Validated Hourly Reanalysis and Satellite Data. Energy, 114:1251-1265.

Pottier, A., Hourcade, J.-C., and Espagne, E. (2014). Modelling the Redirection of Technical Change: The Pitfalls of Incorporeal Visions of the Economy. Energy Economics, 42:213-218.

Revankar, N. S. (1971). A Class of Variable Elasticity of Substitution Production Functions. Econometrica, 39(1):61-71.

Schill, W.-P. and Zerrahn, A. (2018). Long-Run Power Storage Requirements for High Shares of Renewables: Results and Sensitivities. Renewable and Sustainable Energy Reviews, 83:156-171.

Schlachtberger, D. P., Brown, T., Schramm, S., and Greiner, M. (2017). The Benefits of Cooperation in a Highly Renewable European Electricity Network. Energy, 134:469-481.

Schmidt, O., Hawkes, A., Gambhir, A., and Staffell, I. (2017). The Future Cost of Electrical Energy Storage Based on Experience Rates. Nature Energy, 2.

Schröder, A., Kunz, F., Meiss, J., Mendelevitch, R., and von Hirschhausen, C. (2013). Current and Prospective Costs of Electricity Generation until 2050. DIW Berlin Data Documentation (68). Available at: https://www.diw.de/documents/publikationen/73/diw_01.c. 424566.de/diw_datadoc_2013-068.pdf [last accessed: Apr. 6, 2020].

Spiess, A.-N. and Neumeyer, N. (2010). An Evaluation of $\mathrm{R}^{2}$ as an Inadequate Measure for Nonlinear Models in Pharmacological and Biochemical Research: A Monte Carlo Approach. BMC Pharmacology, 10(1):6.

Staffell, I. and Pfenninger, S. (2016). Using Bias-Corrected Reanalysis to Simulate Current and Future Wind Power Output. Energy, 114:1224-1239.

Stöckl, F. (2020). Is Substitutability the New Efficiency? Endogenous Investment in the Elasticity of Substitution between Clean and Dirty Energy. DIW Discussion Paper No. 1886, DIW Berlin.

Stöckl, F. and Zerrahn, A. (2020). Online Material for the Paper "Substituting Clean for Dirty Energy: A Bottom-Up Analysis". Zenodo. Available at: https : //doi.org/10.5281/zenodo. 3940514 [last accessed: Jul. 25, 2020]. 
UBA (2019). Analyse der kurz-und mittelfristigen Verfügbarkeit vonFlächen für die Windenergienutzung an Land. Available at: https://www. umweltbundesamt.de/sites/default/files/medien/376/publikationen/ climate_change_38_2019_flaechenanalyse_windenergie_an_land.pdf [last accessed: Apr. 15, 2020].

Ueckerdt, F., Brecha, R., Luderer, G., Sullivan, P., Schmid, E., Bauer, N., Böttger, D., and Pietzcker, R. (2015). Representing Power Sector Variability and the Integration of Variable Renewables in Long-Term Energy-Economy Models Using Residual Load Duration Curves. Energy, 90:1799-1814.

Welder, L., Ryberg, D. S., Kotzur, L., Grube, T., Robinius, M., and Stolten, D. (2018). Spatio-Temporal Optimization of a Future Energy System for Powerto-Hydrogen Applications in Germany. Energy, 158:1130-1149.

Wiese, F., Schlecht, I., Bunke, W.-D., Gerbaulet, C., Hirth, L., Jahn, M., Kunz, F., Lorenz, C., Mühlenpfordt, J., Reimann, J., and Schill, W.-P. (2019). Open Power System Data - Frictionless Data for Electricity System Modelling. Applied Energy, 236:401-409.

Wiskich, A. (2019). Decreasing Substitutability Between Clean and Dirty Energy. Technical Report 72/2019, CAMA Working Paper.

Zerrahn, A. and Schill, W.-P. (2017). Long-Run Power Storage Requirements for High Shares of Renewables: Review and a New Model. Renewable and Sustainable Energy Reviews, 79:1518-1534.

Zerrahn, A., Schill, W.-P., and Kemfert, C. (2018). On the Economics of Electrical Storage for Variable Renewable Energy Sources. European Economic Review, 108:259-279. 